The World Bank

Washington D.C.

(in collaboration with the United Nations High Commission for Refugees)

\title{
Environmental Impact Assessment
}

\section{First Income Generating Project for Refugee Areas(Pakistan)}

May 1988

Hunting Technical Services Limited

Elstree Way

Borehamwood

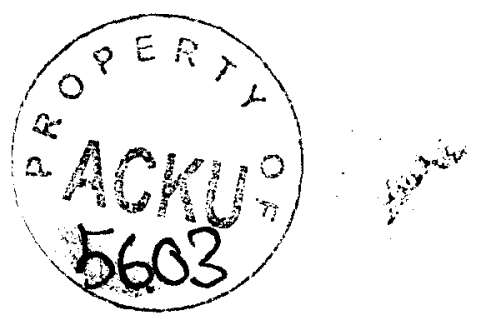

Hertfordshire WD6 1SB

England 
2.

INTRODUCTION/BACKGROUND ................................................................. 3

$2.1 \quad$ Objectives ......................................................................................... 3

2.2 The First IGPRA Program ................................................................ 3

3. ELEMENTS OF ENVIRONMENTAL IMPACT.

3.1 Forestry and Watershed Management Sector ..................................... 4

3.2 Roads Sector................................................................................... 5

3.3 Irrigation and Flood Protection Sector................................................. 5

4.

QUALITATIVE IMPACT ASSESSMENT .......................................................... 6

$4.1 \quad$ General Issues ......................................................................................... 6

4.2 Environmental Impact of Forestry Sector sub-projects in NWFP .......................................................................... 7

4.3 Environmental Impact of Watershed Management sub-projects in Baluchistan ............................................................. 9

4.4 Irrigation and Flood Protection Sector............................................... 11

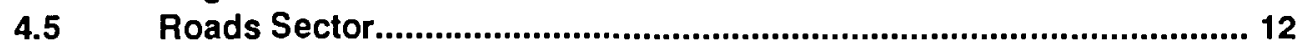

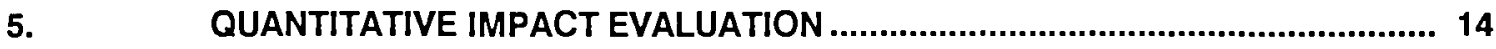

$5.1 \quad$ Primary Considerations ...................................................................... 14

$5.2 \quad$ Provision of Adequate Maps ................................................................... 14

$5.3 \quad$ Forestry and Watershed Management Sector ................................... 15

(a) Water Resources ...................................................................... 15

(b) Vegetation Cover - Forest and Rangeland ................................... 16

(c) Soil Erosion ........................................................................................ 17

(d) Wildlife.............................................................................................. 17

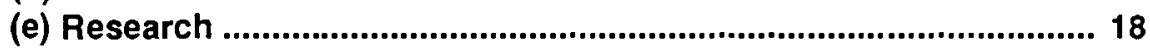

5.4 Irrigation and Flood Protection Sector................................................. 19

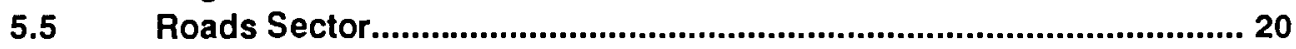

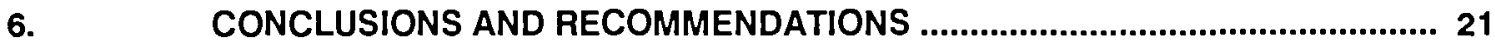

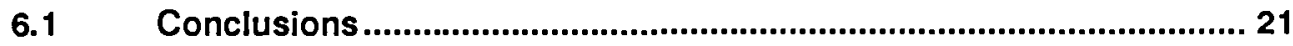

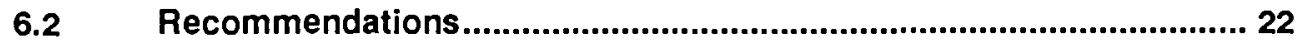

ANNEXES
A. Terms of Reference and Consultant's Itinerary .................................. 24
B. A Note on Rangeland Vegetation in Baluchistan ............................... 25
C. Watershed Management Objectives and Conservation
Treatment Issues in Baluchistan ....................................................... 27

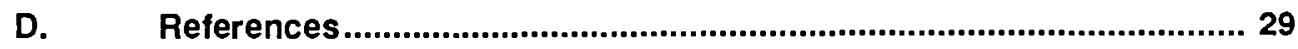




\section{ENVIRONMENTAL IMPACT ASSESSMENT}

\section{FIRST INCOME GENERATING PROJECT FOR REFUGEE AREAS (PAKISTAN)}

\section{SUMMARY}

1.1 This report is concerned with the assessment of the environmental impact, in physical terms, of the first IGPRA program and its component sub-projects. A vital objective of this program was the amelioration of the environmental damage caused by the influx of large numbers of refugees: the long term aim being not only to repair the damage but to create the necessary conditions for sustained improvement.

1.2 The first IGPRA program included sub-projects in three sectors (forestry and watershed management, irrigation and flood control, and roads) in two Provinces (NWFP and Baluchistan). Sub-projects varied widely in character and in size. The forestry and watershed management sector included six relatively large sub-projects, three in each Province. The irrigation and flood protection sector included a large number of small flood protection sub-projects in NWFP (47) and one major irrigation sub-project in Baluchistan. The roads sector included rehabilitation of a large number of canal patrol roads in NWFP (28) and three larger road sub-projects in Baluchistan.

1.3 Potential environmental impact varies greatly both in kind and timing between subprojects in the two provinces, between sectors, and even within each sector. Impact of subprojects in irrigation and flood protection sectors can be - and in most cases has been immediate. The exception here has been the major irrigation sub-project in Baluchistan (Shebo Headworks) where low rainfall since completion has prevented early beneficial impact from being realised. The longer term potential benefit is not in doubt. Beneficial impact of flood protection subprojects in NWFP is clear, including the saving of houses and other buildings, valuable farmland and the protection of roads and bridges.

1.4 Roads projects have also made an Immediate beneficial Impact, though largely in economic or social terms rather than in physical terms - except in one case in Baluchistan (the Surkhab-Khanozal road) where a new road has stimulated orchard development in an area where access was previously limited. The improved access provided by this road could have some negative environmental impact by widening the area from which natural vegetation can be cut or dug up to provide fuel for the very large settlement at Surkhab.

1.5 The environmental impact of reafforestation and watershed management sub-projects is potentially the most important, in the physical sense. Beneficial impacts will, however, be slow to develop and are particularly difficult to evaluate since no monitoring of the kind needed was initiated during the first IGPRA program. Even if it had, however, sufficient data to gutuntify environmental impact could not have been made available in time for the present report. The assessment made, therefore, has been based on direct observations of all six sub-projects, discussion with as many as possible of those concerned, directly or indirectly, and the consultant's own experience.

1.6 Forestry sub-projects in NWFP appear to be having a clearly beneficial impact in regenerating vegetation in areas severely affected by refugees and in re-introducing economically important species (timber-producing trees and mazri palm). The impact so far is perhaps most clearly seen in Soka Nullah and in the Hangu State Forest block of the Kohat Reafforestation and Erosion Control sub-project. Additional beneficial impacts include reduction of soil erosion (including reduction of sediment reaching Tarbela reservoir, in the case of Soka Nullah), attenuation of flood flows and (at Hangu) reduction of the flood hazard affecting the refugee village there. 
1.7 In Baluchistan, assessment of environmental impact of watershed management subprojects is made more difficult because of the range of possible objectives (from groundwater recharge to rangeland improvement and fuelwood production) and the lack of a clear relationship between priority objectives and the protection or conservation treatments undertaken. There has been, and remains, some controversy about the objectives and effectiveness of one particular conservation treatment (the use of contour trenches). More selective use of this treatment is included in Second IGPRA program sub-projects, and specific monitoring aimed at evaluating its benefits, or otherwise. These issues are discussed further in Annex $\mathrm{C}$. Nevertheless, all three subprojects in Baluchistan are demonstrating beneficial impact, most notably so far in regeneration of rangeland vegetation - especially at Kohar and Karkhasa - and in wildlife, at Karkhasa. The Karkhasa sub-project has also demonstrated, after the exceptional storm of August 1986, the effects of watershed management on reducing flooding from the valley.

1.8 In the regional context, overall impact has necessarily been small, but there is evidence of a wider impact, through greater appreciation and cooperation of local people - to date mainly in NWFP - of the benefits of reafforestation and watershed management. Direct evidence was gained, in connection with flood protection and roads projects, of the beneficial impact locally. Within the areas most affected by refugees, however, the beneficial impact of the program - especially in the forestry and watershed management sector - is already apparent. The contrast between regenerated vegetation within sub-project areas and the devastated areas outside them is in all cases marked and in some cases dramatic, offering real hope that full project objectives can in time be attained.

1.9 Quantification of environmental impact has in generai not proved possible. It will in any case be some time before certain sub-projects - essentially those in the forestry and watershed management sector - are able to generate reliable data in this respect. Recommendations are made aimed at ensuring that such data are generated in the future. These recommendations reinforce and in some cases amplify proposals already made by the Bank's Appraisal Mission for the Second IGPRA Program. They include provision of adequate topographic maps, measures for recording surface run-off and soil erosion, and measurement of changes in vegetation in watersheds under treatment. In two cases, both In Baluchistan, instances of damage to subprojects by refugees were noted (the Surkhab road and the Chebo main canal). The recommendations include proposals for rectifying such damage.

1.10 All sub-projects in irrigation and roads sectors in Baluchistan were visited in February 1988 , as were samples of the very large number of small flood protection and canal patrol road sub-projects in NWFP. All sub-projects in the forestry and watershed management sector were also visited, except for one sub-project in Baluchistan (Kohar) which had been seen by the consultant in March 1987. 


\section{$2.1 \quad$ OBJECTIVES}

The Project objectives of the First IGPRA were straightforward. They were to provide employment and thus supplementary income for both refugees and local populations in the affected areas, and in doing so to create viable resources for the longer term benefit of Pakistan or specifically of the two Provinces (North-West Frontier Province and Baluchistan) - on which the First Project was exclusively targetted. (The Second Project has included the Province of Punjab). In addition a linked, and particularly important, objective in the present context was the amelioration of environmental damage caused by the influx of very large numbers of refugees, estimated in 1987 to be at least 3.15 million, 2.8 million of these being registered by UNHCR. The program aimed not only at repair of such environmental damage but also, in the longer term, for sustained improvement. report.

It is evaluation of the effects of this last objective which is the purpose of the present

\subsection{THE FIRST IGPRA PROGRAM}

As already indicated, the First IGPRA Program was directed solely towards generating activities in North West Frontier Province (NWFP) and Baluchistan, the Provinces then most affected by refugees. The sub-projects, in three sectors, were as follows:

Forestry \& Watershed Management
Roads
Irrigation and Flood Control
2.2.1 Forestry and watershed management sub-projects were designed to rehabilitate forests
and watersheds which had deteriorated severely as a result of the additional pressures (mainly for
fuelwood and the grazing of livestock) generated by the refugees. Road sub-projects were
orientated to construction of new roads, to the rehabilitation of roads damaged by the transport of
supplies to refugees or to the upgrading or rehabilitation of secondary and canal roads. Irrigation
and flood control sub-projects were planned to provide flood protection to irrigation channels,
villages, infrastructure (and in some cases to the refugee settlements themselves), and to arable
land. In one case, the sub-project was concerned with the rehabilitation and enlargement of a
canal system (in Baluchistan).

2.2.2 All sub-projects were required to be technically viable, labour intensive, and close to refugee villages and sources of local labour. They were also required to be capable of completion within the three year project period.

2.2.3 All those sub-projects in the forestry and watershed management sector, plus those concerned with rehabilitiation of road damage caused by transport of supplies to refugees, were directly related to either degradation of the natural environment or of infrastructure caused by the influx of refugees. Flood protection projects have been less directly related to damage caused by refugees, but have significant local impacts, including the provision of work for refugees in nearby camps. This report concentrates on sub-projects in the forestry and watershed management sectors, but sub-projects in other sectors have also been included in, the review. 


\title{
3.1 FORESTRY AND WATERSHED MANAGEMENT SECTOR
}

Sub-projects in this sector were of three quite distinct kinds:

\author{
Reafforestation and Erosion Control Schemes in NWFP (2 sub-projects) \\ Mazri palm plantations, also in NWFP (1 sub-project) \\ Watershed Management Schemes, in Baluchistan (3 sub-projects).
}

3.1.1 (The Second IGPRA Program includes a fourth kind of project in this sector, canal-bank or road-side irrigated line plantations, in the Punjab and NWFP).

3.1.2 Distinction between the kinds of sub-project is important in relation to environmental impact. The two Reafforestation and Erosion Control sub-projects, both in NWFP, were Soka Nullah Watershed and Kohat Reafforestation. Both involved extensive replanting of trees $(22,500$ acres and 6,000 acres respectively) plus parallel conservation works. The principal direct elements of environmental impact expected would be restoration of ground and tree cover by protection and direct planting, reduction of soil erosion caused by the degeneration of overall plant cover through over grazing, cutting and burning, and reduction of surface run-off resulting in more stable stream flows and reduction of the flood hazard. An important medium and longer-term benefit would be timber production: first for fuel wood and poles, and later for larger timber. Since Soka Nullah lies in a higher rainfall area, and Kohat in the semi-arid area of NWFP however, this last benefit would be of a substantially different order for each sub-project.

3.1.3 The single mazri palm sub-project (a concept extended to additional sub-projects in the Second IGPRA Program) was designed largely to rehabilitate and increase production of this valuabte plant, and by introducing protection (by fencing and guards) to improve overall plant cover in a severely degraded and denuded area. Mazri palm fronds are cut and used commercially for mats, baskets and string: the impact of refugees had been not only the over-exploitation of this locally valuable resource but in many instances the complete elimination of the palms themselves, roots being dug up as sources of fuel. The impact of this kind of sub-project would therefore be the restoration of the natural vegetation generally with some impact on excessive surface run-off of rainfall. Fodder for livestock and controlled grazing could be additional benefits.

3.1.4 In Baluchistan, the sub-projects in this sector are more directly related to overall watershed management and - for obvious climatic reasons - had much less emphasis on forestry as such. It can be argued, in this context, that the NWFP sub-projects (excluding mazri plantations) would also be more orientated towards watershed management as a whole: a point that is discussed later (4.2). The three watershed management projects in Baluchistan are essentially similar though of different extent - 4,500 acres at Maslakh, 3,000 acres at both Kohar and Karkhasa. Karkhasa sub-project was added in the second year of the program. The major original objective in each case was groundwater recharge, to be achieved by a combination of soil and water conservation measures, re-seeding and replanting, and protection by fencing. This major objective, and its validity, is discussed further (4.3). Other impact elements included better control of surface run-off in these seriously denuded watersheds (an element associated with the major objective), regeneration and improvement of rangeland, limited production of fuelwood, erosion control and, as a secondary element, a contribution to reducing flood damage lower down the system. Environmental impacts of these projects should all be beneficial.

3.1.5 Both in NWFP and Baluchistan, there are substantial potential impacts on wildlife, mainly beneficial. In some cases there may be beneficial impacts on recreation and general amenity. 
In NWFP, all road sub-projects (28 in number) were essentially concerned with rehabilitation or improvement of canal patrol roads, the work consisting mainly of remedial earthworks and provision of shingle or gravel surfaces. These canal roads, unlike those in Punjab and Sind, are not restricted as to traffic. They are therefore of considerable importance to the general pubiic. Heavy traffic, accentuated by the needs of the refugees, has resulted in substantial deterioration of this valuable road network, with some attendant damage to the canals themselves. The canal roads may even become impassable during certain periods of the year. The potential impact of sub-projects in this sector can therefore be highly beneficial. All such sub-projects are executed by the Irrigation Department.

3.2.1 In Baluchistan, the three road sub-projects included construction of a new road, upgrading of an existing secondary road, and the rehabilitation of a section of a national highway.

3.2.2 The environmental impact of roads sub-projects will be almost entirely beneficial, with some minor reservations in relation to the impact of improved access on natural vegetation.

\subsection{IRRIGATION AND FLOOD PROTECTION SECTOR}

47 relatively small sub-projects in this sector were included in the First IGPRA Program for NWFP. These involved building spurs, bunds and walls designed to save villages, agricultural land and infrastructural elements from the impact of floods: all were therefore flood protection schemes rather than irrigation projects. All should therefore have, or will have, the direct beneficial effect planned for. Any indirect effects from the forestry sector sub-projects on reducing the flood hazard would depend on the extent to which there is any clear geographical linkage between the different sector sub-projects.

3.3.1 Only one project in this sector was included for Baluchistan. This was of a quite different character: the rehabilitation of the Shebo canal system and desilting of the main canal. The principal impact here would clearly be the additional water to be distributed. Watershed management sub-projects could again provide secondary benefits, if geographically related, by reducing floods and sedimentatlon. 


\section{QUALITATIVE IMPACT EVALUATION}

\subsection{GENERAL ISSUES}

4.1.1 Most of the sub-projects in both roads and irrigation and flood protection sectors are quite small-scale. Their impact will therefore be entirely localised, even though of actual or potentially major benefit in that context. In the forestry and watershed management sector, subprojects are relatively large in areal extent and therefore have a potentially wider impact, both directly and indirectly.

4.1.2 Such wider impacts do, however, need to be considered in the broader or regional context. The Soka Nullah sub-project covers about $40 \%$ of the 56,000 acres of the total Soka Nullah watershed - the Second IGPRA sub-project here will increase this coverage to almost $60 \%$, which provides for a potentially major impact. It should be remembered, however, that Soka Nullah, though significant in itself, represents only a very small fraction of the huge and vital Tarbela Watershed. Even the World Food Program project, initiated in 1977/78, which had covered 129,000 acres by 1983 - a very substantial area - has affected only about $0.03 \%$ of the total Tarbela watershed. (This figure excludes the higher altitude section of the watershed which is beyond the scope of afforestation or soil conservation measures).

4.1.3 Even at the local level, evaluation of environmental impact is difficult unless clear records of the situation existing pre-project are available and - especially in the context of watershed management - if sub-projects are not related to particular watersheds or sub-watersheds. This last point becomes especially important when it comes to making quantitative, as opposed to qualitative, assessments. It will be referred to again (5.1).

4.1.4 At Soka Nullah, the whole watershed has been divided into sub-units on a map, though only on a plan map rather than a contoured map. Even this level of mapping does not exist at Kohat (the other relevant project in NWFP), nor does it for any sub-project in Baluchistan except Karkhasa, where a small-scale contoured map exists - but prepared by another agency under a different program. This general lack of adequate mapping, both as an obstacle to impact evaluation and to effective project management as a whole, was raised as an important issue by the Appraisal Mission for the Second IGPRA Program, and provision has been made in that program for new mapping.

4.1.5 Two of the three sub-projects in Baluchistan - Kohar and Karkhasa - were well related to natural watershed units. The third - Maslakh - was less so. Once again, it is possible to provide some appreciation of local impact, but the wider impact must inevitably be small bearing in mind the area covered by the sub-projects in relation to the environmental degradation problems created by refugee incursion generally. One area - and it is a particularly important area - where a wider impact may be both major and more readily evaluated is the Quetta Valley. At present the only sub-project affecting the Quetta Valley is Karkhasa, but Second program sub-projects totalling 20,000 acres in all (nearly seven times the area of Karkhasa) could start to make a really important contribution to the rehabilitation of this particularly badly affected region.

4.1.6 Although it is evident that sub-project environmental impacts must be small in the regional context, their indirect impact seems likely to grow and therefore have wider effects. In spite of initial indifference or even opposition by local people, there is now considerable evidence of interest - now that there can be some direct appreciation of the effects of reafforestation and protection - in the work which has been undertaken. In Soka Nullah, for example, local people have benefitted from increased amounts of fodder available from grass cutting, with material from thinning of forest plantations becoming available before long. As most land treated is privately owned, local people will also benefit directly from eventual timber production. A demand for tree seedlings has sprung up, mainly for quick-growing broad-leaved species and fruit trees at present. 
The change in local attitudes, if by no means universal at present, is both encouraging in itself and likely to provide a more favourable climate for the development of Second Program sub-projects. The direct impact of the small areas (in the regional context) so far treated has initiated spin-off effects which could become quite widespread, and seem likely to be accelerated as Second Program work proceeds.

\subsection{ENVIRONMENTAL IMPACT OF FORESTRY SECTOR SUB-PROJECTS IN NWFP}

4.2.1 In the higher rainfall foothills zone of NWFP, represented in the First IGPRA Program by the Soka Nullah sub-project, the principal elements of environmental impact can be listed as follows:

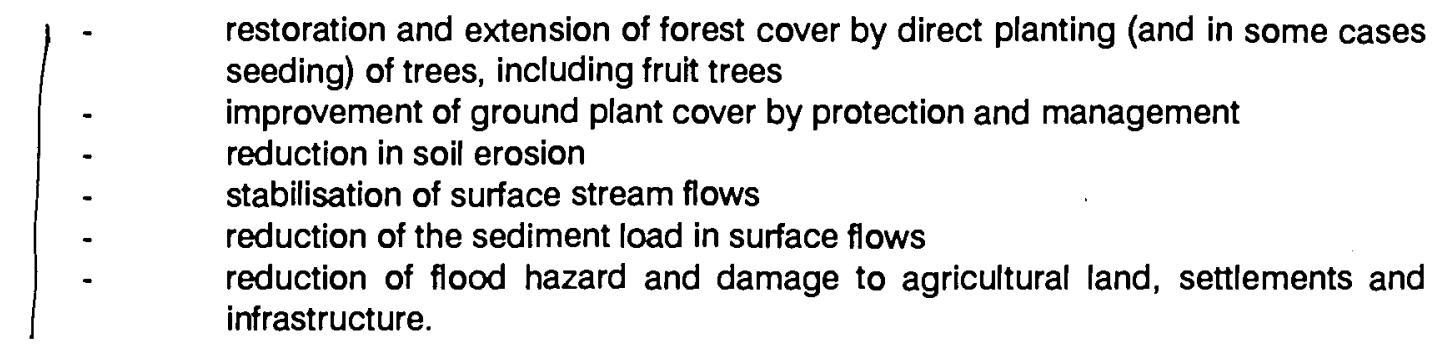

4.2.2 All these impacts are potentially positive. The restoration and extension of forest cover results in directly quantifiable economic benefits in terms of timber, but the protective value of extended forests, in relation to the last four potential impacts listed, cannot be separately assessed. Improved ground cover, especially of grasses, should produce quantifiable economic benefits (in the form of cut fodder) but only in the earlier years of forest establishment. Better ground cover would again contribute, with forest cover, to the last four listed impact elements though again not susceptible to separate assessment, at least at present.

4.2.3 In addition, control of soil erosion and the reductlon of sediment load In surface flows would be of direct benefit to the Tarbela reservolr. Stabilisatlon of surface stream flows, on the other hand, could result In rather less water reaching the reservoir - though not necessarily so.

4.2.4 Control of soil erosion Is of course affected both by the establishment of improved plant cover and by the construction of physical soil conservation works. Very substantial improvement in plant cover has been achieved throughout the area protected and in some places natural regeneration of trees (shisham) was observed in February 1988. In the Soka Nullah, conservation works consist primarily of stone check dams in the steeper gullies and nullah training walls in the bed of the Soka Nullah itself. The stone check dams in areas of steeper slopes have been properly constructed and sited and appear to be effective. There is however substantial erosion observable in the steeper parts of the watershed, in many cases from poorly constructed agricultural terraces and, at the extreme head of the valley, from road construction. Nullah training walls have been constructed mainly to protect nullah-bed plantations, but in some cases to reduce river bank erosion. Smaller stone spurs are currently being constructed, in the lower reaches of the valley, to further reduce this bank erosion. These works appear to be effective, though two substantial training walls in the upper reaches of the valley - where the nullah bed is relatively narrow and where floods can be both rapid and deep - have been damaged by the flood flow under-cutting them. Some repairs had been effected, but in this part of the valley better foundations for the walls may be needed, with the possible addition of concrete aprons at the base of the walls - as is Irrigation Department practise elsewhere.

4.2.5 When Second IGPRA Program planting is complete, nearly $60 \%$ of the total sub-project area will have been treated, thus very greatly reducing the erosion hazard. There will remain the problem of erosion from the steeper agricultural terraces, which will eventually need to be tackled possibly by persuading the owners to plant them with trees, something which has already been done, for example, on agricultural land close to or within the nullah bed. 
4.2.6 The overall progress with First IGPRA Program planting, as seen when the area was visited in February 1988, has been good. Overall losses of young trees have been estimated at around $50 \%$, with better establishment in the earlier years and particularly heavy losses due to the very dry weather since the spring of 1987 . This dry weather seems to have been especially hard on young chir pines planted in the summer 1987 season. Vigorous efforts are being made to replace* these losses, with adequate replacements being available from the established nurseries. Nullahbed plantings had made impressive growth since March 1987, when the project was previously visited, especially in the case of Robinia plantings. Well established chir pines were also observed in February 1988, though there must be some concern about damage caused by porcupines - to which young pines up to about five years old are especially vulnerable. The Forest Department currently offers a bounty of Rs $\mathbf{5 0}$ per head for taking these animals.

4.2.7 In referring to soil conservation measures, it is possible that additional kinds of treatment may be needed on some sub-projects in the Second IGPRA Program. It was noted, during field visits in 1987, that there seemed to be three principal causes of soil erosion in the higher altitude and higher rainfall areas of NWFP. These included the breakdown of poorly constructed agricultural terraces on steep hillsides, erosion resulting from over-exploitive logging practices by timber concessionnaires, and gullying and river bank erosion of the loess and alluvial soils of the valleys. Measures to counteract active guilying (by 'gully-plugging') have actually been included in the specification for one Second program sub-project. The effectiveness of this kind of treatment, combined with re-establishment of vegetation through protection, has been demonstrated - more than 40 years ago - in the Kanshi basin, where the soils are mainly loess. (The Kanshi is a right bank tributary of the Jhelum, joining the main river above Mangla Dam). Dealing with erosion caused by over-exploitive logging is beyond the scope of the IGPRA Program, but control of erosion caused by breakdown of agricultural terraces which, at higher altitudes, often appeared to have been abandoned, could be achieved by construction of contour bunds. Additional protection in this context would be provided by the use of vetiver grass (Vetiveria zizanioides); which has proved very successful in India.

4.2.8 Although at present none of the potential environmental impact elements at Soka Nullah is quantifiable, with the exception of the direct benefits from forestry, the overall impact of the work so far undertaken must be beneficial. It is perhaps worth noting, in this connection, that when the sub-project was visited on a day of heavy rain in March 1987, surface flow in the nullah bed was almost free of sediment. It is, however, the heavy storms of the monsoon period which generate the larger surface flows and cause most of the erosion.

Impact elements which are seen as potentially quantifiable are discussed in Section 5.

4.2.9 The reafforestation and mazri sub-projects in NWFP (in Kohat) are best dealt with together. The two types of sub-project cover some 11,000 acres, divided into nine or ten separate areas. These range in size from over 2,000 acres to less than 200 acres. Most of these areas occupy gently sloping land requiring no specific soil conservation measures. Treatments consist solely of planting or seeding of trees or mazri palms, either in individual pits or shallow trenches, and overall protection by fencing and paid guards. Apart from the direct benefits from trees and mazri-palm fronds (see 3.1) the beneficial environmental impacts include the restoration and improvement of forest and rangeland (including natural stands of mazri palm) which had become severely degraded under pressure of the refugees in nearby camps, and potential provision of cut fodder and, in the longer term, grazing for livestock. Some wildlife benefit is also already observable, mainly in the form of an increase in partridges.

4.2.10 The exception, in this area, is the largest block of the Kohat reafforestation project, covering over 2,000 acres in Hangu State Forest. This area comprises much steeper land and had become severely degraded by the activities of refugees from the large camp at the base of the hills. Soil conservation works (stone check dams) were built, in addition to the planting or sowing of several tree species. With protection by fencing and guards in addition, the impact of the sub- 
project has been dramatic: trees well established, grasses, herbs and shrubs regenerating naturally and strongly. It seems likely also that the regenerated plant cover will have had a beneficial impact on the flooding of seasonal torrents which pass through the village area, which also benefits from a small piped water supply. Wildlife, again evidenced mainly by the presence of partridges, also seems to be on the increase.

\subsection{ENVIRONMENTAL IMPACT OF WATERSHED MANAGEMENT SUB-PROJECTS IN BALUCHISTAN}

4.3.1 All three sub-projects in this sector in Baluchistan are sited in approximately similar environmental conditions - relatively high aititude sites and arid climate - and can therefore be considered as a group. Environmental impact of these sub-projects is discussed at rather greater length, since this is the one sector where some reservations have been expressed about possible negative impact. It should be emphasised, however, that such reservations relate to specifics of watershed treatment measures and not to the need to ameliorate conditions in the upper watersheds in general.

4.3.2 The main elements of environmental impact in this sector can be listed as follows:

$\begin{array}{ll}\text { - } & \text { increased recharge of groundwater } \\ \text { improved rangeland vegetation, with potential for increased livestock } \\ \text { production } \\ \text { increased production of firewood } \\ \text { attenuation and reduction of flood peaks, and thus reduction of flood damage } \\ \text { in lower parts of the system } \\ \text { reduction of soil erosion } \\ \text { - } \quad \text { enhancement and restoration of wildlife, improved recreational opportunities } \\ \text { and general amenity. }\end{array}$

4.3.3 The original rationale for the three Baluchistan sub-projects was based on the potential for enhanced groundwater recharge. Enhanced recharge was to be achieved by use of a number of types of conservation works, the most important being the construction of open trenches, arranged along the contour. The validity of this approach has been questioned by a hydrological consultant appointed by the Bank in March 1987, and is discussed further in Annex C. This consultant (Evans) did, however, support the continued use of contour trenches as a means of controlling damaging surface run-off from larger storms.

4.3.4 The reservations expressed about contour trenches in the context of direct environmental impact (as opposed to their effectiveness in relation to groundwater recharge or control of surface run-off) are rather different in character. The upper watersheds in the area of Baluchistan in which Karkhasa and Kohar sub-projects were located (Maslakh is rather different and is discussed separately, see Annex C), and also where most Second Program sub-projects are located, have rather characteristic land forms. The valleys generally consist of steep rocky upper slopes (sometimes almost sheer and almost devoid of soil cover) succeeded by sloping colluvial or alluvial (piedmont) fans, composed of mostly rather coarse material and with a surface layer of larger stones and even boulders. Even when denuded of plant cover, these fans (which are where contour trenches are placed) have a natural resistance to sheet erosion as the stony surface slows down surface flow, and have relatively high infiltration rates. Surface run-off tends to be mintmal except at the time of very heavy storms, and erosion levels are not high. Restoration of plant cover further improves the slowing of surface flows and therefore increases infiltration - reduced somewhat, in the latter case, during periods of rapid plant growth. Concern has been expressed that by digging trenches, which obviously break the natural 'armoured' surface of the alluvial fans, a new cycle of soil erosion could be initiated. 
4.3.5 A secondary effect of the disturbance caused by the trenches could be the possible invasion of unwanted 'weed' plants. Stable rangeland tends to be dominated by perennial grasses and low woody shrubs, In Baluchistan. Dyksterhuis ${ }^{2}$ has, in the context of range management, rather usefully characterised rangeland plants (especially grasses) as increasers, decreasers, and invaders. Decreasers are climax perennials which cannot tolerate grazing pressure and are most palatable to livestock: they tend to diminish under grazing pressure. Increasers are part of the perennial climax, may even gain ground under moderate pressure, but under the heaviest pressure even these may go. Invaders are weedy species normally restricted to small disturbed areas in rangeland in good condition, but which are capable of spreading everywhere when grazing is excessive or the range vegetation seriously depleted. Clearly the disturbance occasioned by the contour trenches, combined with the degenerated state of most rangeland, provides the opening for such invaders: but there is no evidence to date that this has occurred.

4.3.6 Improvements in rangeland vegetation and the resulting increased potential for livestock production can both in principle be quantified, though this is not yet possible for the First Program sub-projects. Measures necessary to achieve such impact or benefit quantification are described in 5.3. Benefits, In economic terms, for fuelwood production have been projected for some Second program sub-projects, but this was not done for those in the First Program. Environmental impact benefits from tree and shrub establishment cannot, however, be separated from the benefits of rangeland improvement generally - except perhaps, where trees have been established for specific amenity purposes - as to some extent they have been at Karkhasa. The effects of treatment have been generally beneficial: at both Kohar and Karkhasa the recovery of rangeland vegetation - in terms of percentage coverage rather than species composition, which could not be checked at the time - was Impressive when the sub-projects were visited in March 1987 and February 1988.

4.3.7 The contribution of the sub-projects to flood control cannot be quantified, but must be beneficial. It may be possible to quantify the contribution of Karkhasa sub-project to flood hazard in Quetta Valley, both because of its direct geographical and hydrological linkage to the Valley and because the topography of the sub-project lends itself to direct measurement of surface outflows from it. This is also referred to in 5.3.

4.3.8 The most obvlous beneficial Impact on wildlife is at Karkhasa. Protectlon of this area has resulted In a significant increase in wildlife, perhaps partly because its upper end adjoins the National Park, with its protected reservoir of wildlife. Karkhasa, with its striking landscape, also offers important recreational and amenity benefits, being so close to Quetta City. The only critical comment which can be made in this context is that the contour trenches, at least in their early years, do have a negative impact on landscape values: this should reduce over time as plant cover increases and the trenches themselves tend to fill in.

4.3.9 In general, it should be said that the watershed management treatment undertaken on the three sub-projects so far implemented should also be beneficial to water management in these watersheds and in the region in general. The principle of encouraging treatment as high up in the system as possible cannot be faulted. So far as water management is concerned the treatments at present being undertaken are certainly complementary to the delay action dams being installed (for example In Quetta Valley) and, as the number of such sub-projects builds up during the Second IGPRA Program, could contribute significantly to flood control and recharge from schemes based on diversion weirs and recharge channels.

4.3.10 The installation of contour trenches is the only really controversial issue affecting these sub-projects, in relation to environmental impact. Some final observations may be worthwhile in concluding the discussion. Firstly, there is as yet no evident of serious breakdown of the trenches leading to increased erosion, even after the very big storm of August 1986, except in very localised areas (in Karkhasa) where trenches were dug in places where soft rocks (shales) outcrop. Trenching of such areas has been recognised as a mistake and will not be done in future. Secondly, there is as yet no clear evidence either that trenches encourage the invasion of unwanted plant species or, as is also claimed, that they encourage the re-establishment of vegetation (except in the case of deliberately planted trees and shrubs). Only systematic 
observation, as has been recommended, will resolve this question. Finally, any potential erosional hazard from trenching will be lessened in Second IGPRA program sub-projects because overall densities of trenching have been reduced and, if Evans' recommendations are followed, their density, or spacing, will be related to slope - which is not the case at the present time. One cautionary point should be made in the context of relating density to slope: to be effective in controlling run-off, higher densities of trenching will be needed on steeper slopes and an upper limit for any such treatment should be established. An upper limit of $50 \%$ was proposed by Evans.

\subsection{IRRIGATION AND FLOOD PROTECTION SECTOR}

4.4.1 47 sub-projects were completed in this sector in NWFP in the First IGPRA Program. Only a small sample (4 sub-projects) of these schemes could be visited in the time available. These included the Pir Bala flood protection scheme, near Peshawar: flood protection at the Khazana refugee camp; the Kaskoroona sub-project at Mardan; and the Mukam Nullah (Garhi Daulat Zai) sub-project near Mardan. All were impressive: well executed stone walls or spurs, wire reinforced, and with obviously beneficial impact. At Pir Bala, the project works have protected a village threatened by river bank erosion, protected a bridge and road, and farmland. Works at Khazana camp have protected the houses of refugees from destruction or damage by floods. At Kaskaroona (a suburb of Mardan) the Kalpani river had destroyed numbers of houses and threatened many more: the long high wall has now removed this threat. At Mukam Nullah, an exceptionally long wall now prevents erosion of the river bank: erosion which had already destroyed a section of the road and was threatening the school, water tower, and houses. What was particularly striking was the evident appreciation and gratitude of the local peopie, who made their feelings plain both individually and in groups: a farmer expressing his gratitude for the saving of his land; large numbers of people (at Kaskaroona) making their feelings plain at the effects of the protective stone wall on the security of their housing.

4.4.2 All this positive Impact, which applies equally to all other sub-projects In this sector, was in direct contrast to the tragic situation at Kandara Dara Daud, at the confluence of the Adezai and Khali rivers, where the sub-project had to be abandoned after works had been destroyed by abnormal monsoon floods in 1986. Now most of the large village has been lost to the river, and bank erosion Is rapidly destroying good agricultural land.

4.4.3 There was only one sub-project in this sector in Baluchistan. This Involved remodelling of the main flood canal from Shebo Headworks, In Pishin District, plus silt clearance In the two distributary canals, the Saranan Minor and the Shadezal Minor. The work also involved masonry work on the main canal immediately below the Headworks, lining of the main canal for a short distance at the head of the canal, and provision of diversion gates where the two minor canals offtake from the main canal. Work was completed during 1986, in spite of some interruption (causing some local damage, which was repaired, caused by the flood in August of that year). The work appears to have been carried out efficiently and to a high standard.

4.4.4 The Shebo Headworks and canal system was completed in 1888. The canal system was (and is) supplemented by four storage tanks, designed to store any excess water when it is not needed for irrigation - generally the months December to February. The total area of cultivable land commanded by the system was 16,000 acres, with rather more than 5,000 acres expected to be cultivated annually. In practice, it does not seem that, after inception of the scheme, water was ever available to cultivate more than between 2,500 and 3,000 acres (in the late 1890's and early 1900 's); most of the crops grown being in the winter (rabi) season.

4.4.5 The period between 1956 and 1962 was one of good rainfall, and comparatively larger acreages were irrigated, the highest figure being just over 4,700 acres in 1960-61, with nearly 80 per cent of this area under rabi crops. After 1962, the area irrigated annually gradually declined, due to a combination of low rainfall and the silting-up of the system. The storage tanks had also largely silted up. In the years 1983 to 1985 no crops at all were irrigated. 


\subsection{PRIMARY CONSIDERATIONS}

5.1.1 Monitoring and evaluation of almost all direct impact elements depend on the availability of accurate topographic maps, with the partial exception of surface run-off measurement. The absence of such sub-project maps is a principal, but not the only, reason why so little of the environmental impact of the First Program sub-projects can be assessed in other than broad qualitative terms. The approach to the preparation of the necessary maps is set out In more detail below (5.2), with specific reference to forestry and watershed management sub-projects. Flood control and roads sub-projects do not suffer from this kind of deficiency in mapping, since they are site-specific and the preparation of the necessary plans is integral to their design.

Later sections discuss the needs of different elements of quantifiable impact evaluation, if this is to become possible in the future - as it should. These needs are discussed sector by sector. Special investigations or experiments are also discussed.

\subsection{PROVISION OF ADEQUATE MAPS}

5.2.1 The point has already been made that it is the forestry and watershed management subprojects (excluding only, and even then not entirely, the mazri palm sub-project) which offer the greatest and longest term beneficial environmental benefits. Adequate maps are vital for proper selection, planning, monitoring and evaluation and general management of the sub-projects. With the exception of Soka Nullah such maps are lacking in both NWFP and Baluchistan. The same situatlon applles In the case of the Second Program sub-projects, but provision has already been made for this deficiency to be put right.

5.2.2 The existing 1:50,000 scale General Topographic series maps of Pakistan should have provided a sufficient basis for the rational selection of sites and limits of sub-projects, which should have been directly related to the whole or part of single sub-watersheds. In the First IGPRA Program three of the sub-projects were properly related to physical watershed units (Soka Nullah In NWFP and Kohar and Karkhasa In Baluchlstan); one partially so (Maslakh in Baluchistan): and two (Kohat and Hangu Mazrl In NWFP), hardly at all. The number of sub-projects In this sector In the Second IGPRA Program has been substantlally Increased, but thelr siting In relation to physical watershed units Is still not clear. Once again the connection between project sites and watershed units Is stronger in Baluchistan than In NWFP, with two of the 5 representing clear physical subwatershed units, two being quite closely related, and only one barely so related at all. Of the 9 relevant sub-projects in NWFP (four additional ones, mazri plantations and irrigated line plantations do not have watershed management implications), only two are closely related to physcial watershed units and one of these is an extension of Soka Nullah. Even Soka Nullah itself does not in fact represent altogether a single watershed unit, since it comprises part of the watershed of the Siran river. This situation could still be rectified: it is important in connection with future evaluation and management that it should be.

5.2.3 The next stage in mapping should be the provision of 1:25,000, or even better, 1:10,000, scale maps for each sub-project: by enlarging and, where necessary, updating the 1:50,000 series maps. The area covered by new maps for each sub-project should include the whole natural watershed unit or units within which the project is located. Provision for preparing such maps for all First IGPRA Program sub-projects has been allowed for in Second Program estimates. These maps should be then developed as 'resource' maps (showing different land-form units, soils, vegetation types etc as a basis for management planning and monitoring). Where specific conservation treatments are involved - especially contour trenches as in Baluchistan - these project maps are especially vital, since the density and spacing of such works should be related to slope if they are to be fully effective. 


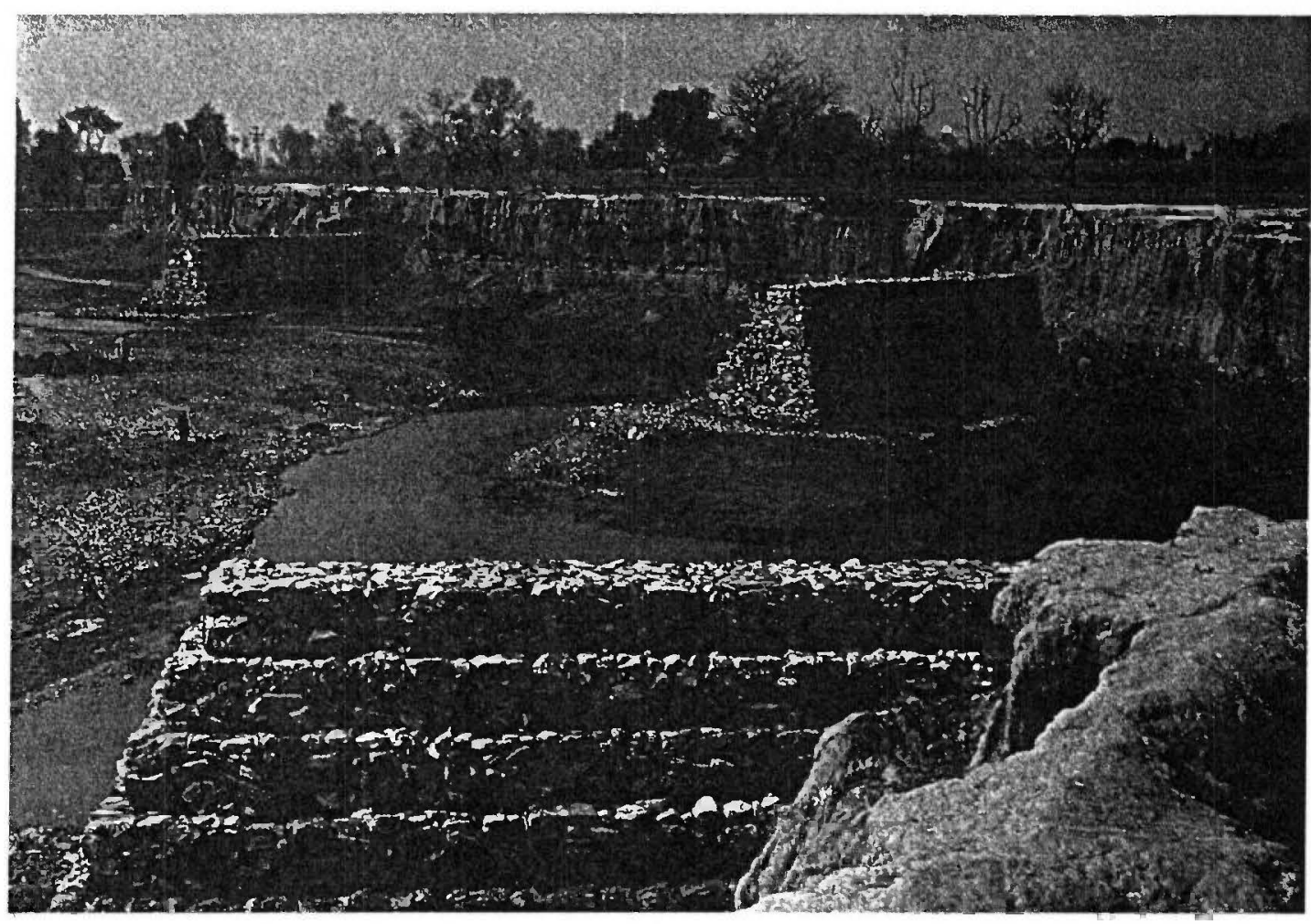

Stone spurs protecting agricultural land from bank erosion at Pir Bala, NWFP.

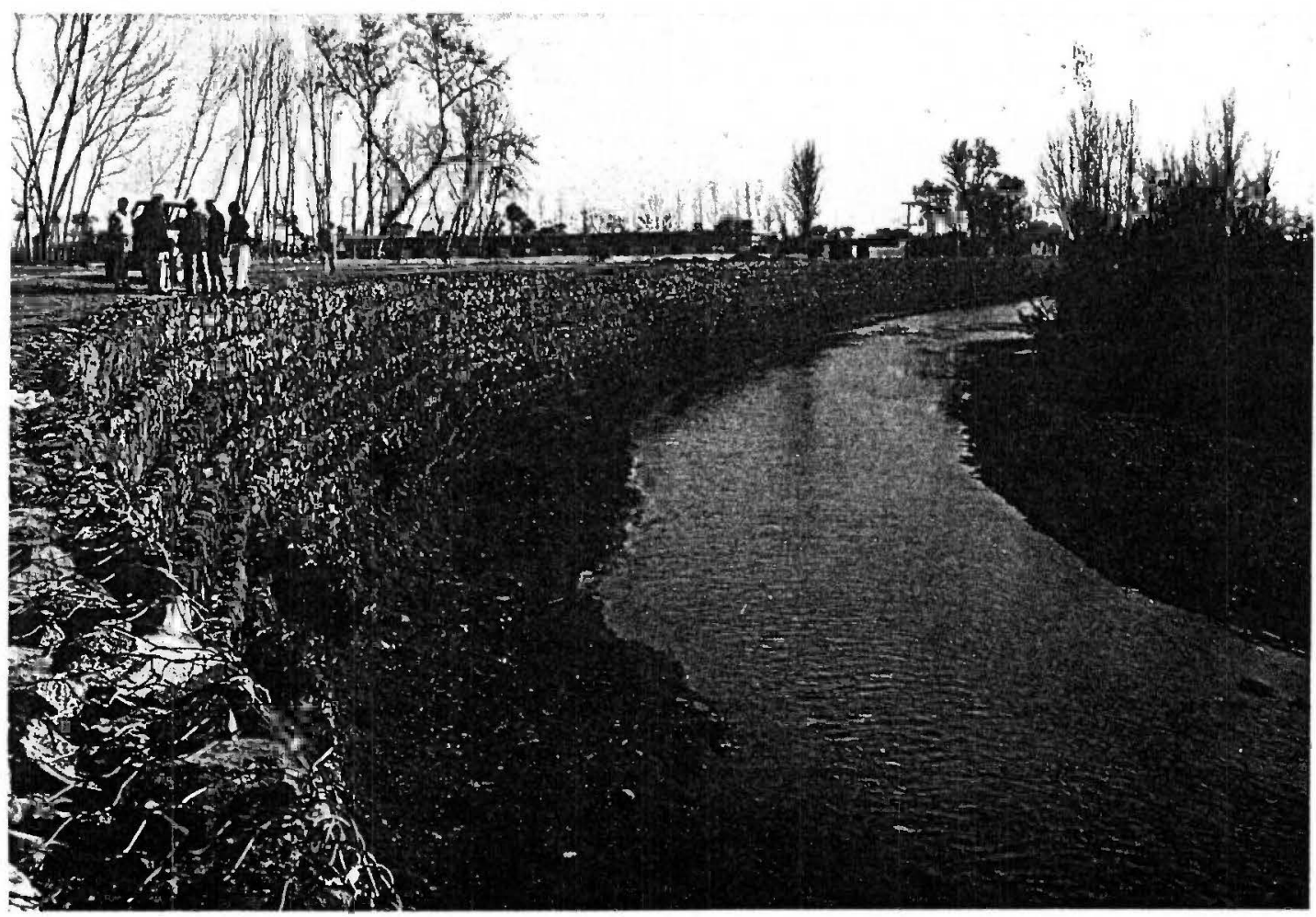

Protection wall on the Mukam Nullah, Garhi Daulat Zai, NWFP. 


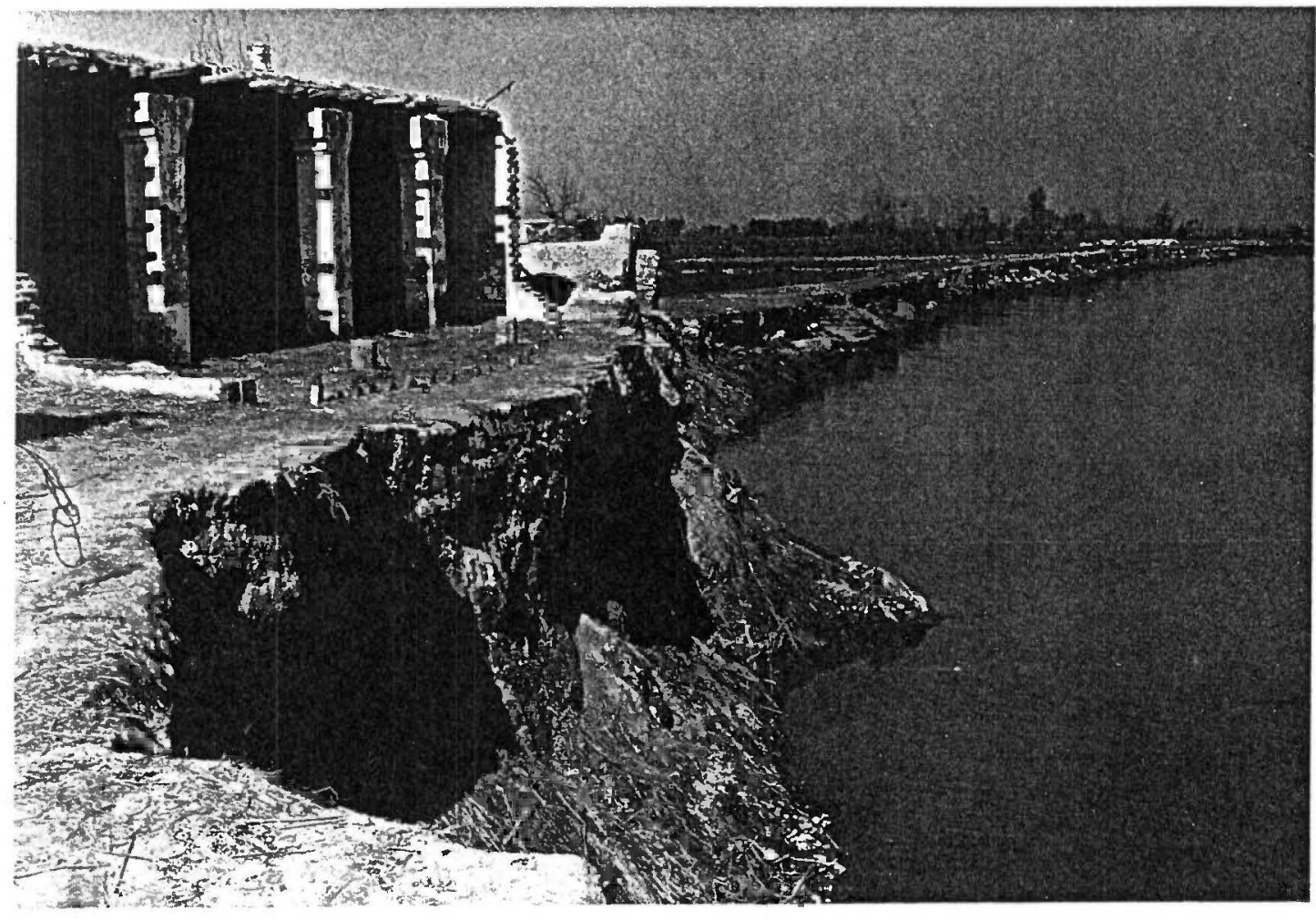

Remnants of village destroyed by floods, Kandara Dara Daud.

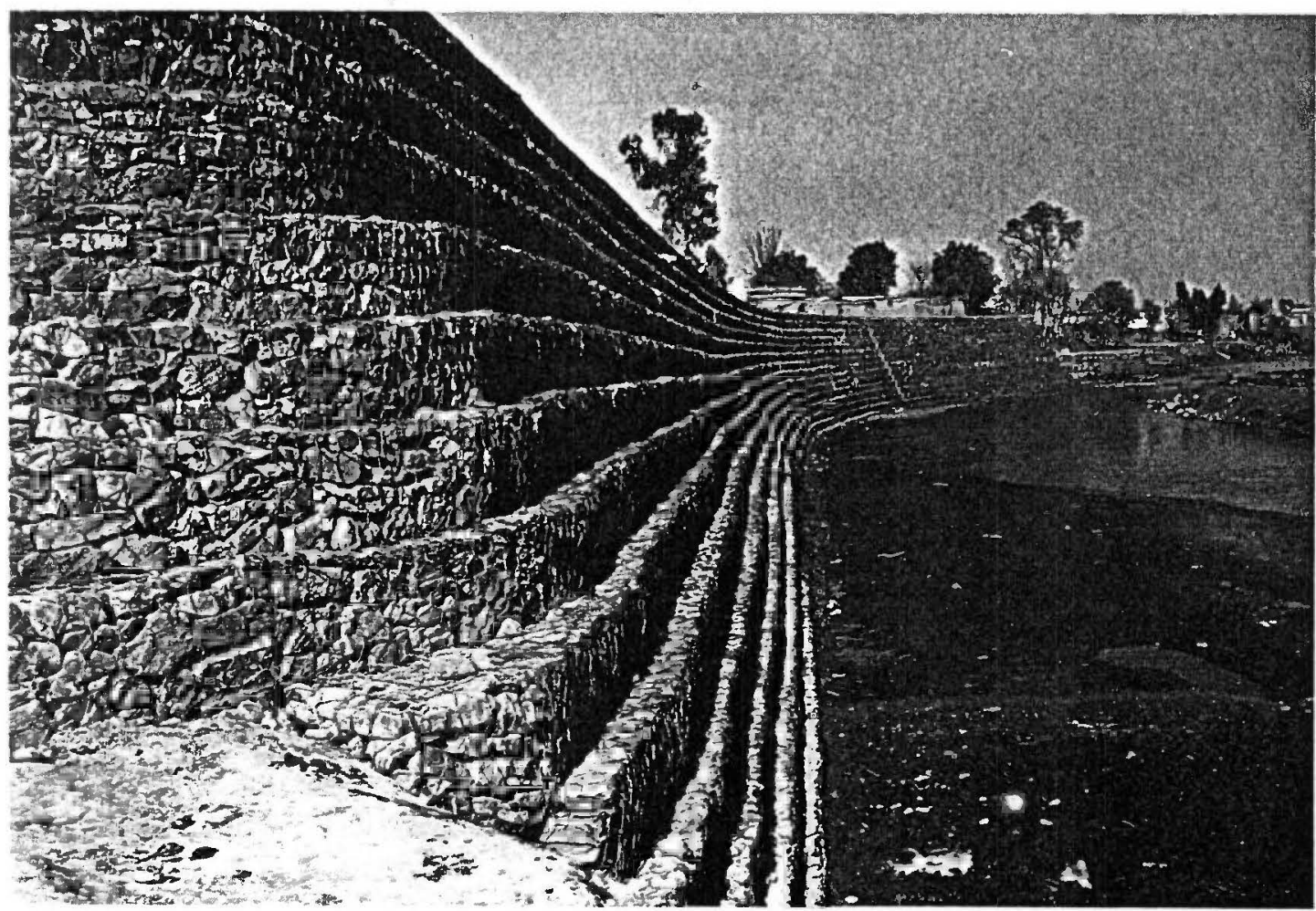

Protection of wall saving housing at Kaskoroona, across the Kalpani river from Mardan. NWFP. 


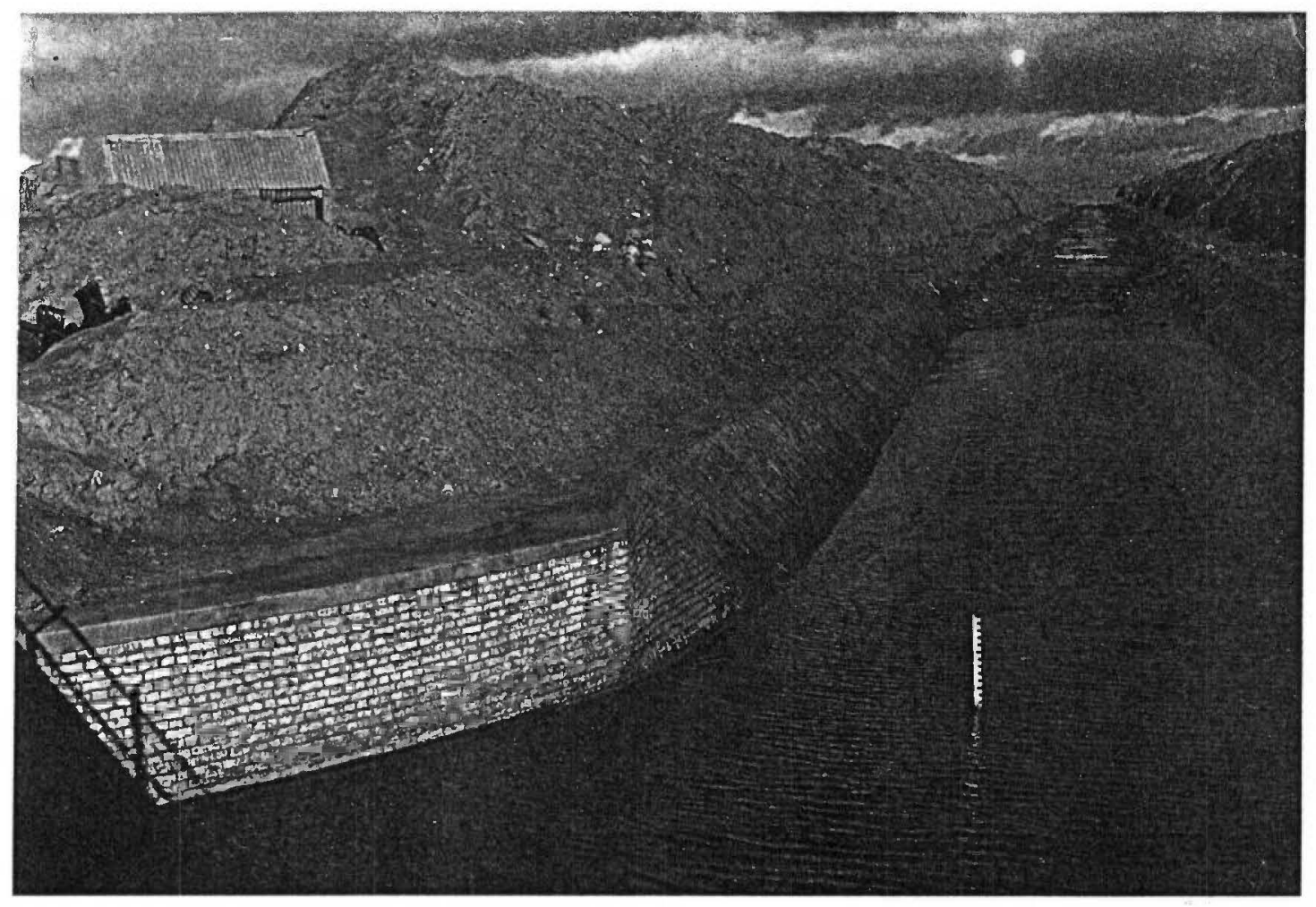

Remodelled and desilted main canal, Shebo Headworks, Baluchistan.

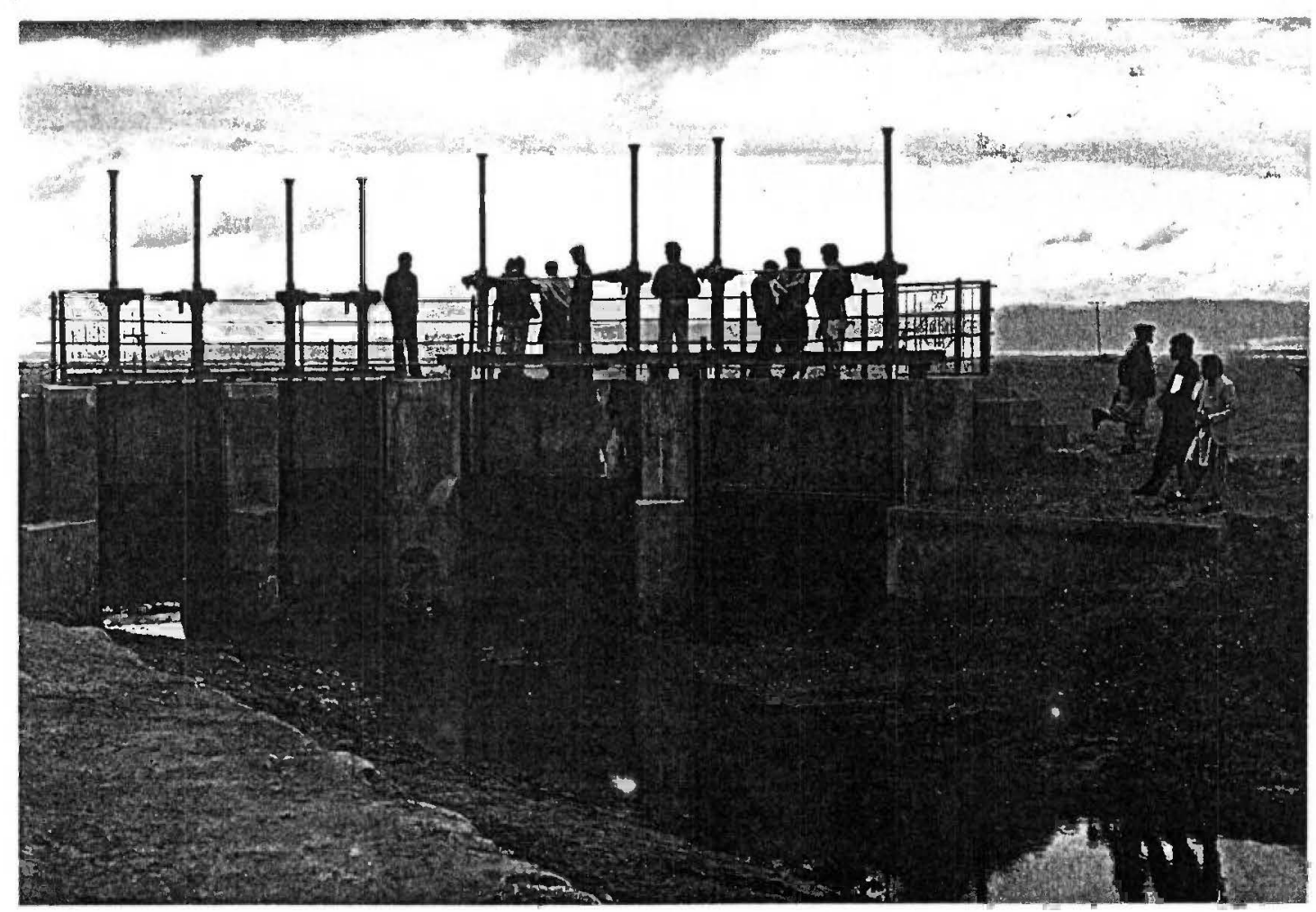

New gates on main canal, distributing water to two minor canals, Shebo Headworks project, Baluchistan. 


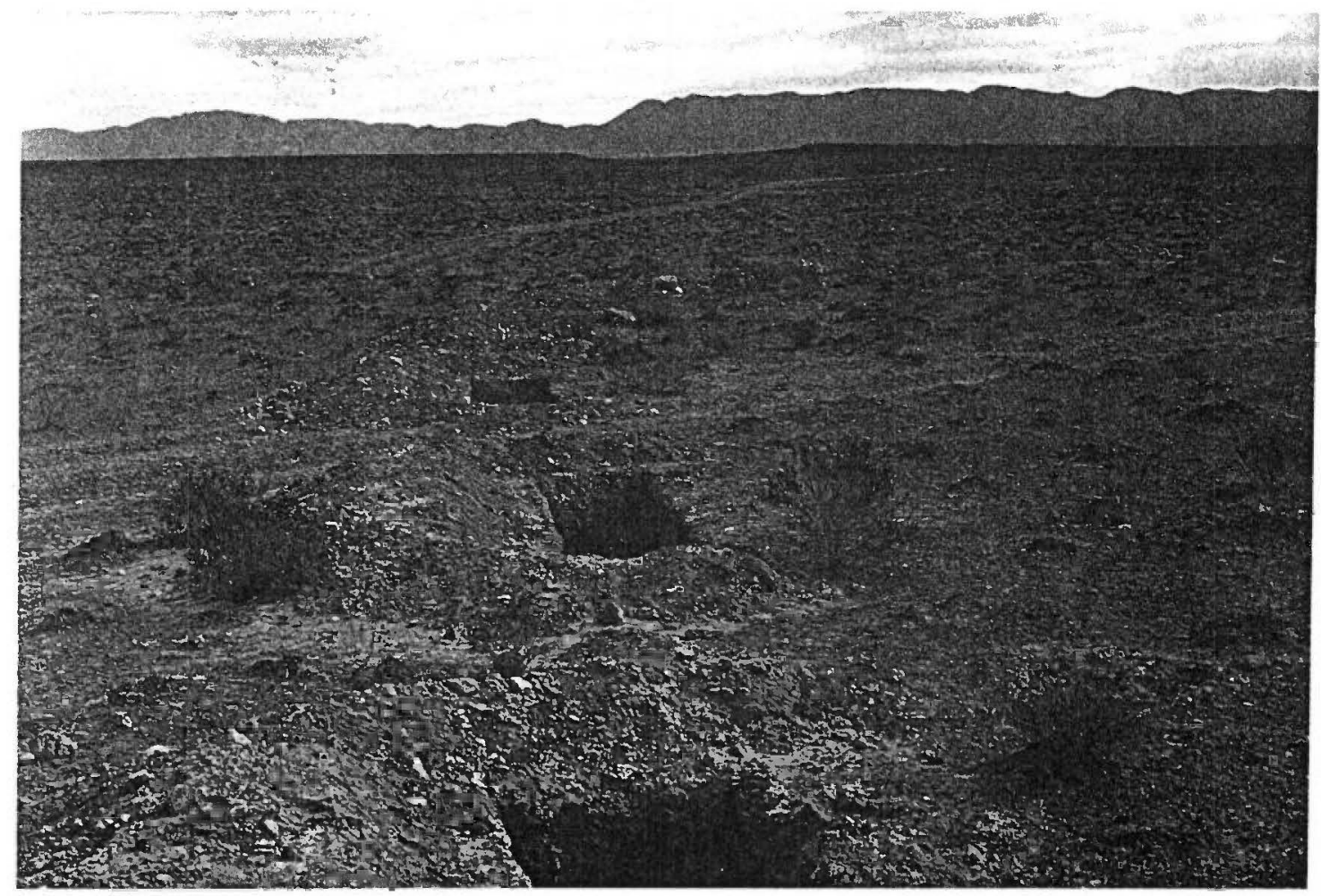

Contour trenches on Maslakh sub-project, Baluchistan. Showing slow regeneration in an area stripped by refugees.

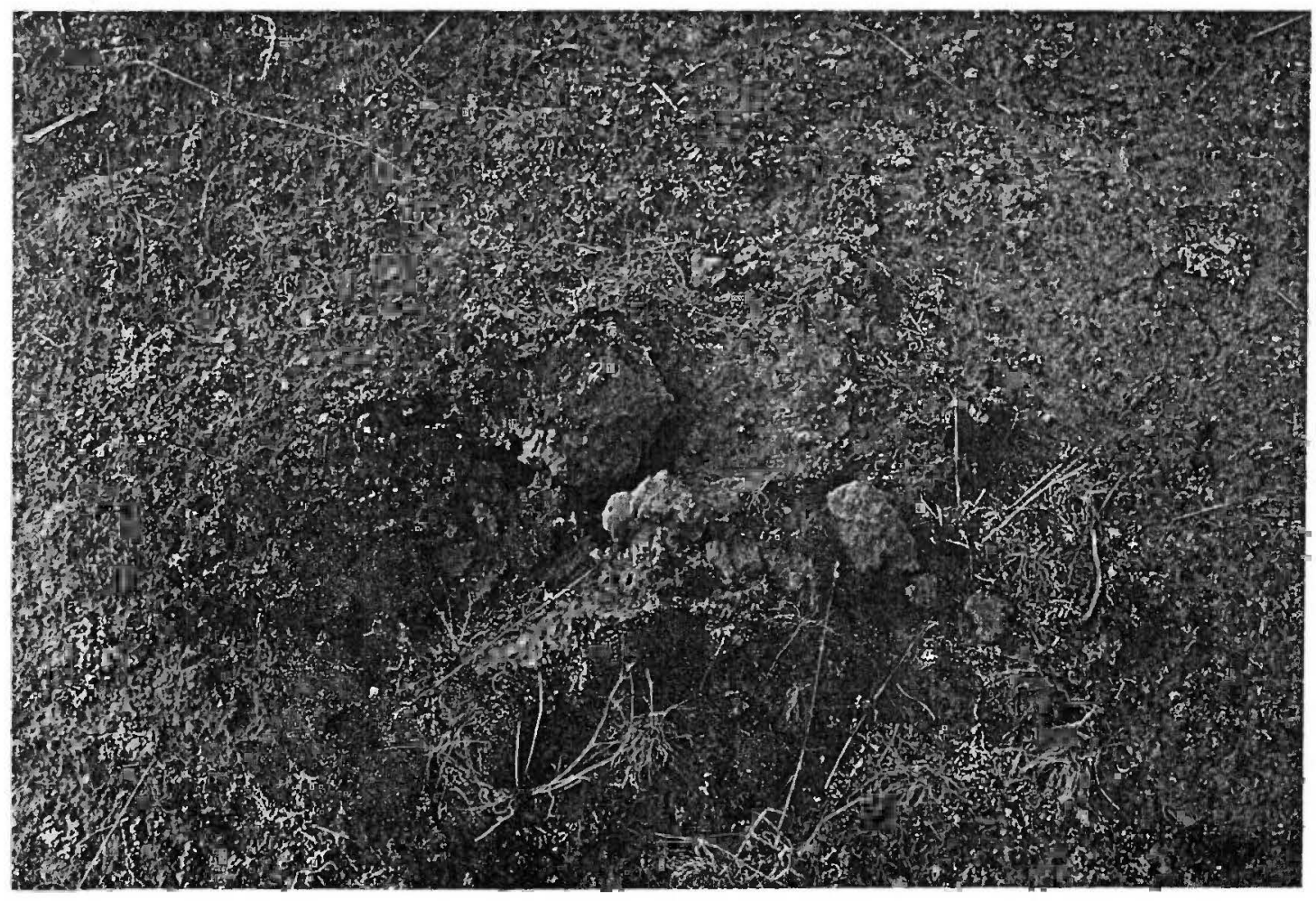

Evidence of total removal of perennial plants by refugees, Maslakh. 


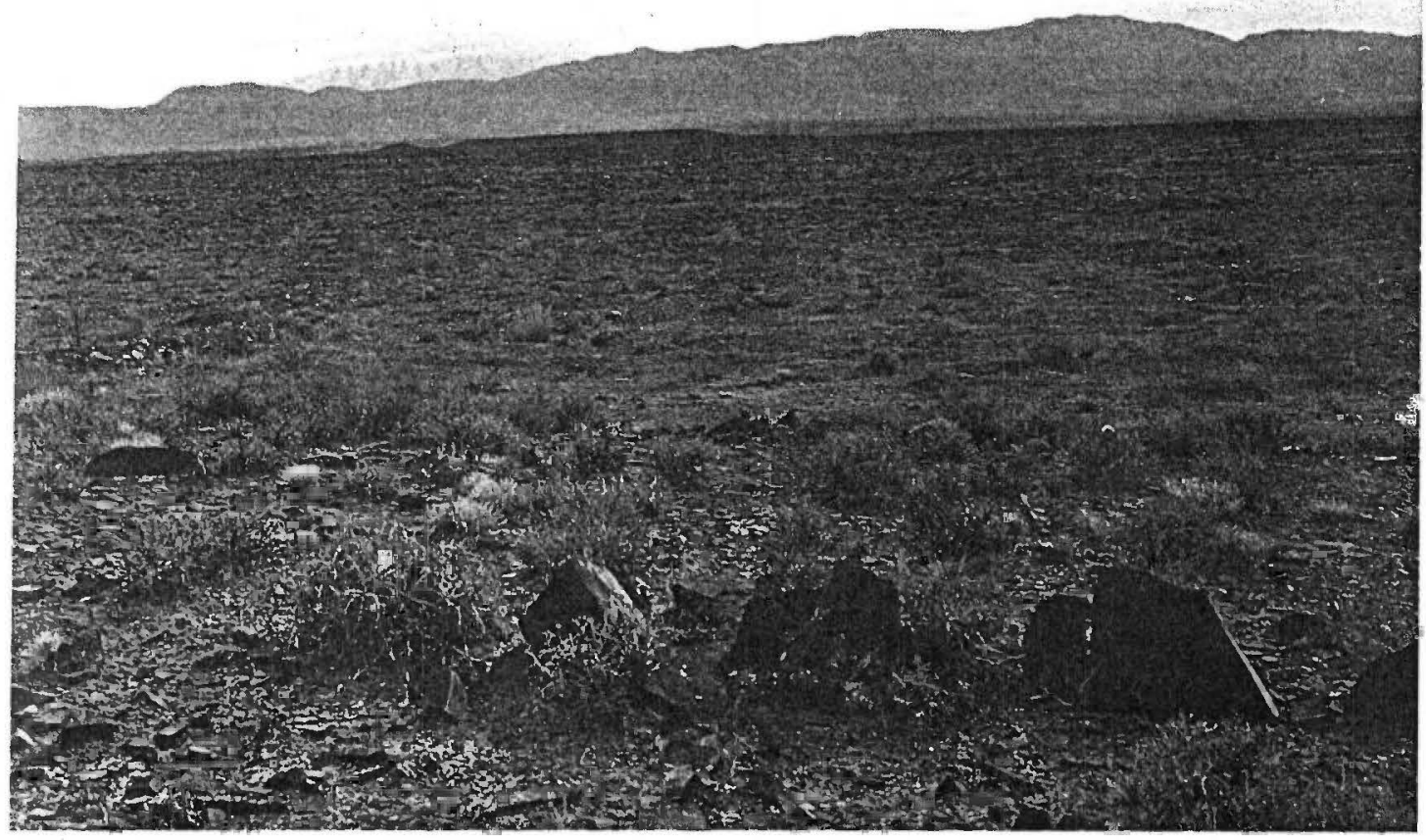

An area of better recovery of vegetation, Maslakh.

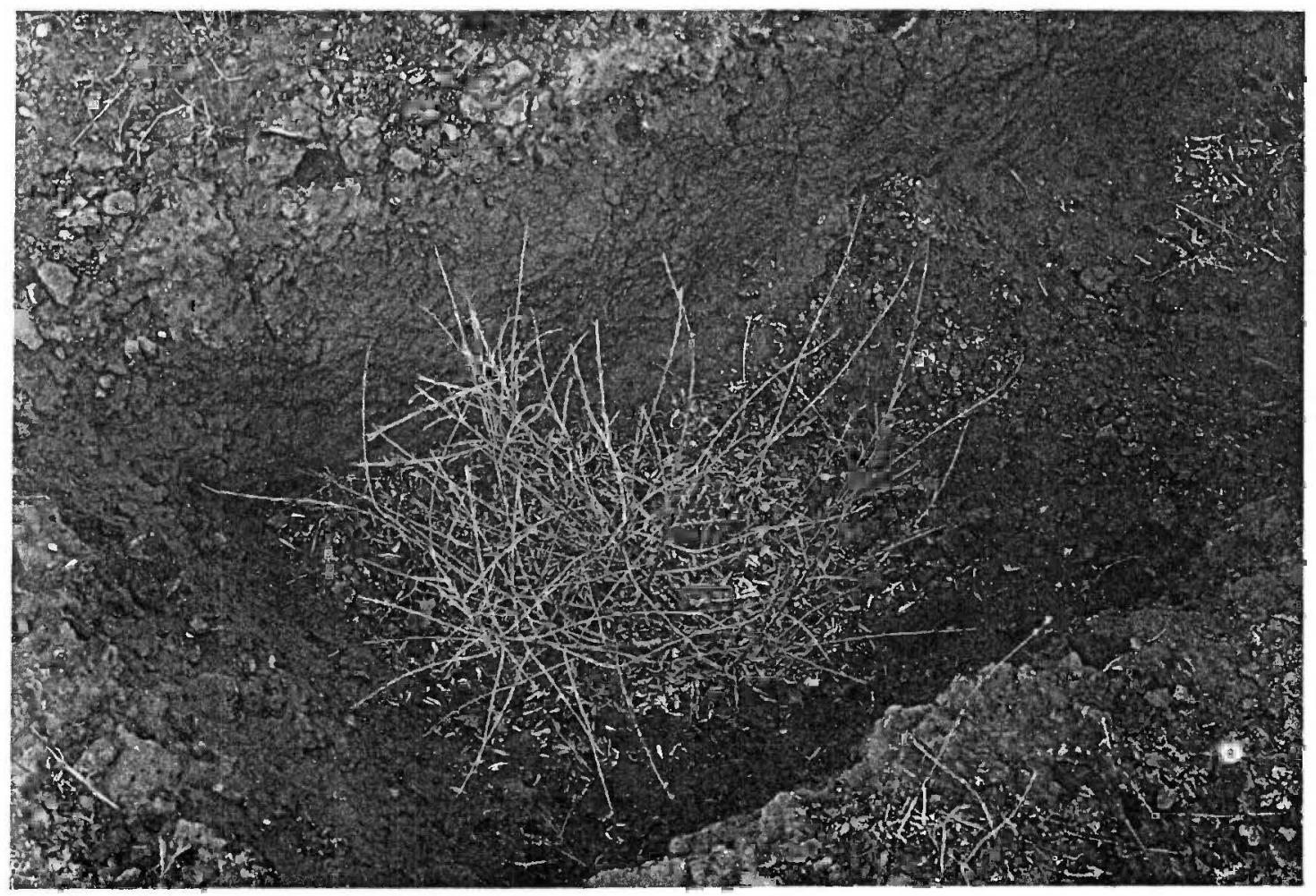

Haloxylon, planted in a contour trench at Maslakh, and growing well. 


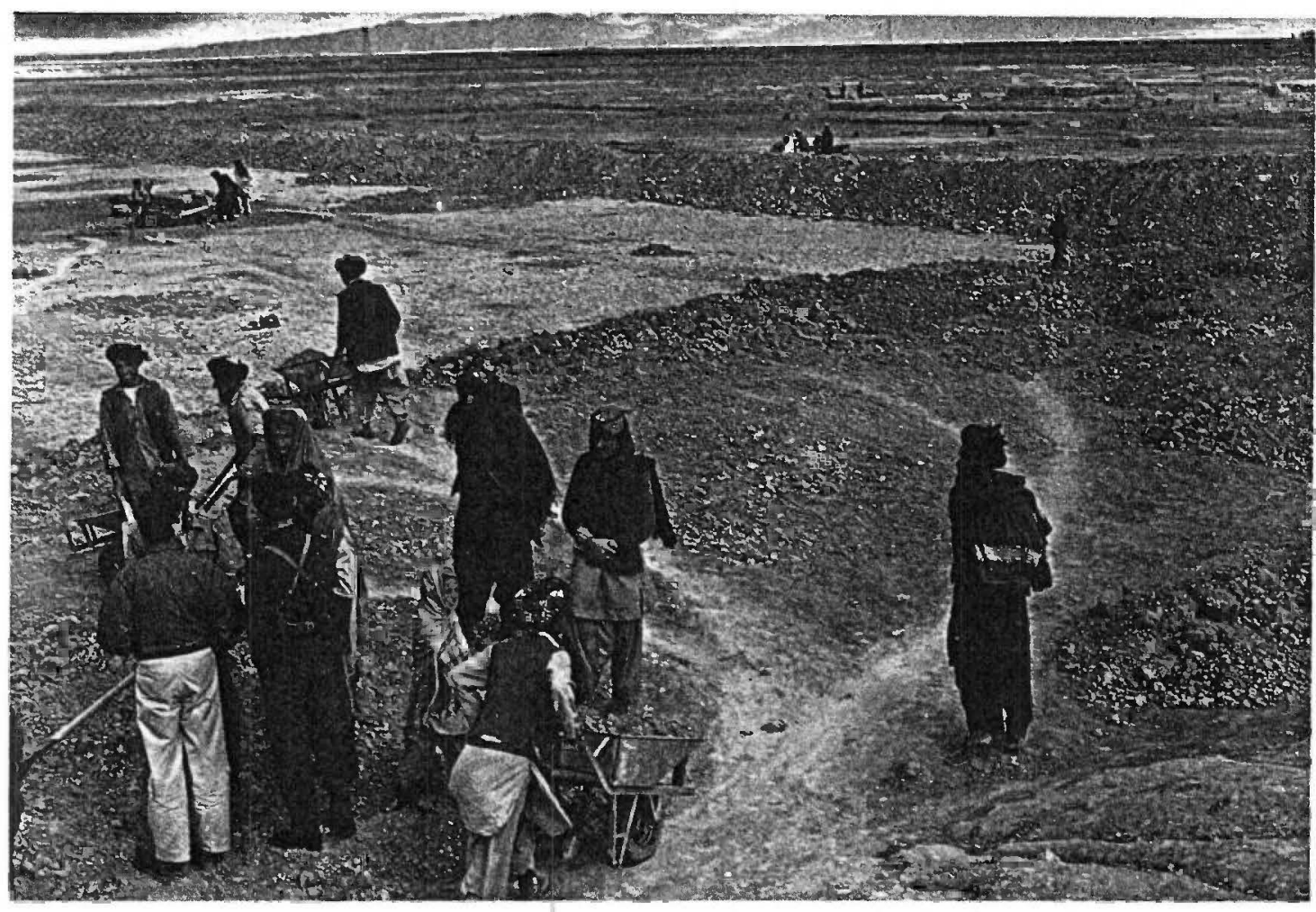

Afghan labour removing silt from storage tank No.3, Shebo Headworks project, Baluchistan.

\section{ROADS SECTOR}

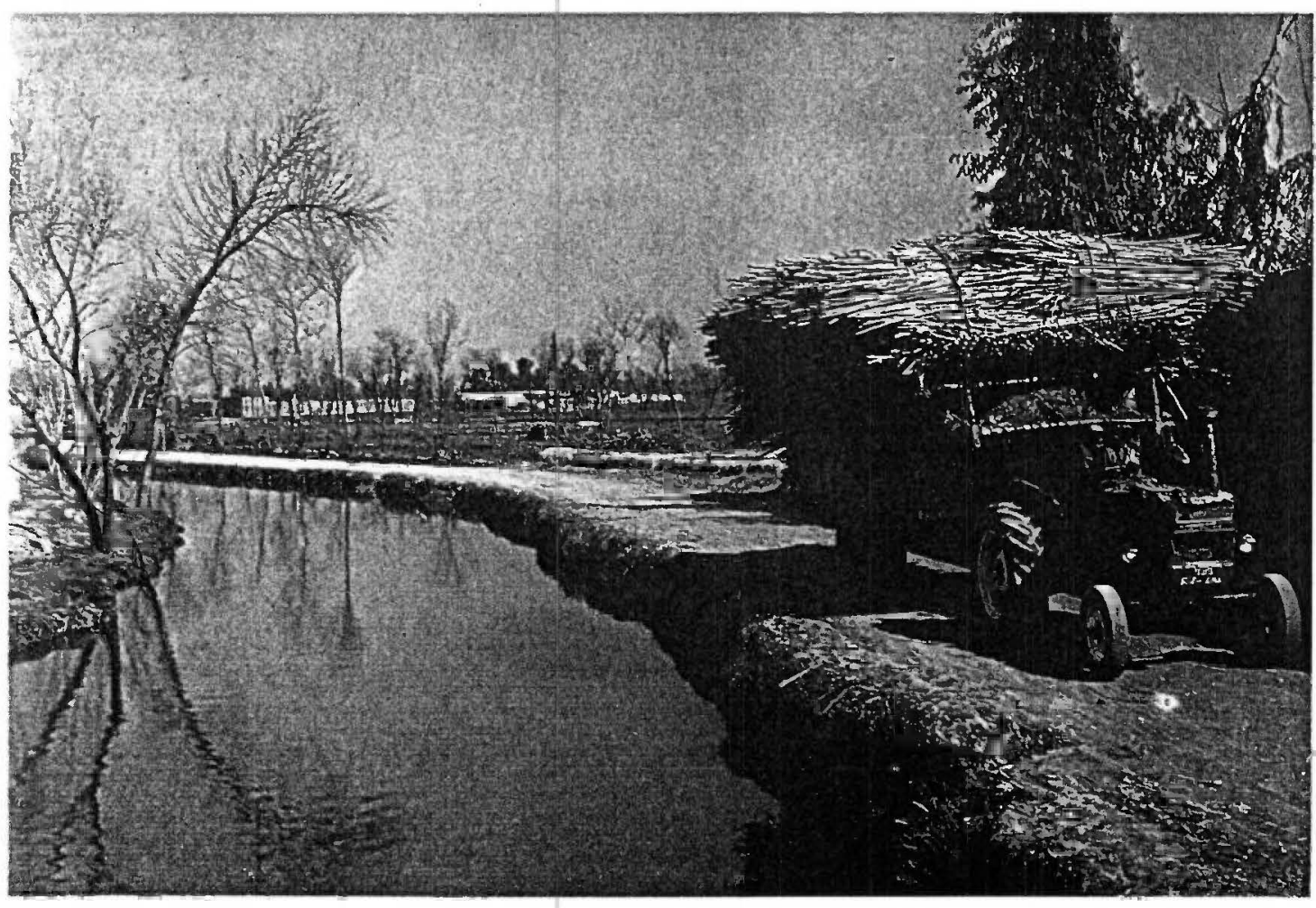

Upgraded canal road at Zardad, NWFP, now being used by mechanical transport. 


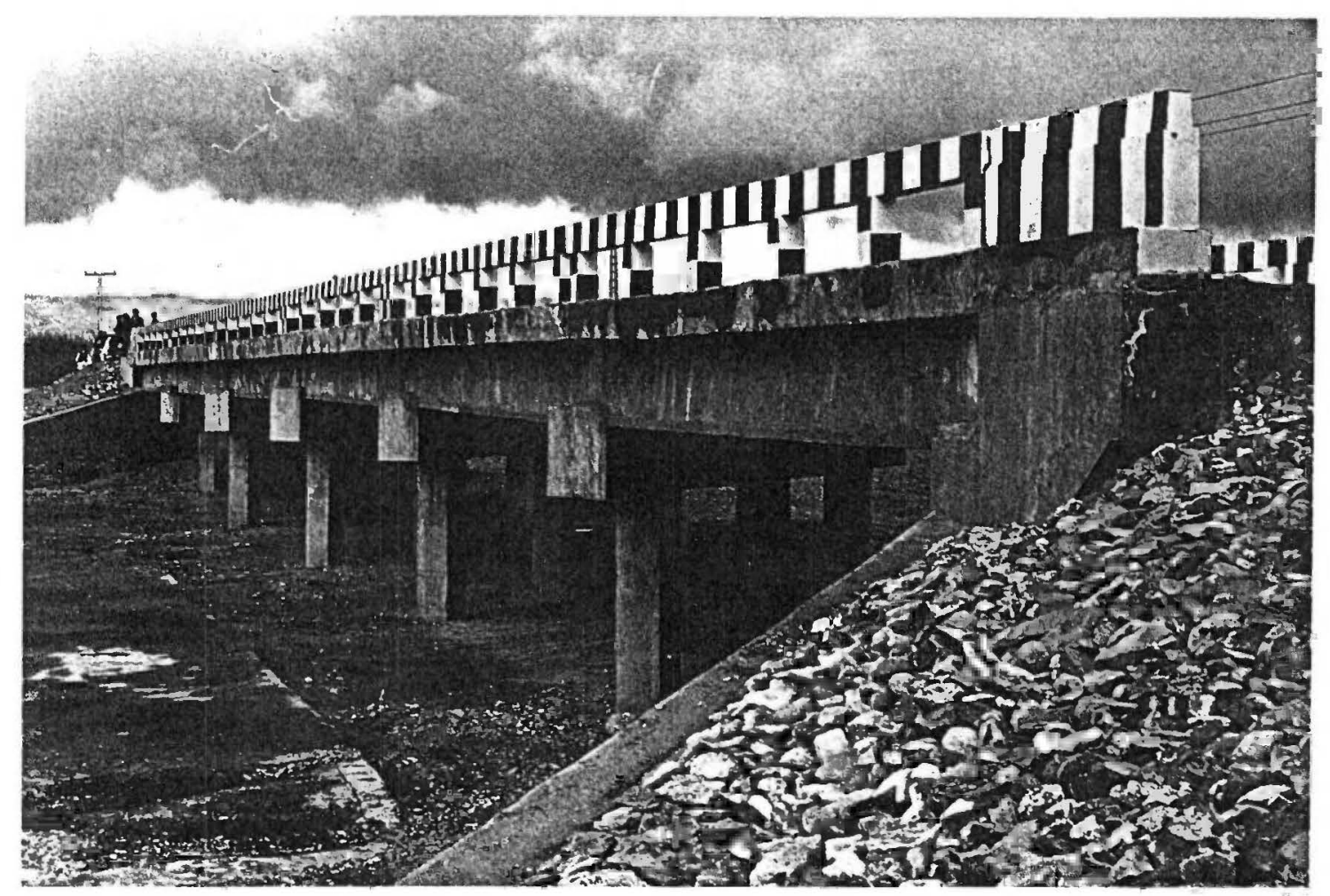

The largest of the four bridge or culvert structures on the renovated and improved section of the Quetta Chaman road, Baluchistan.

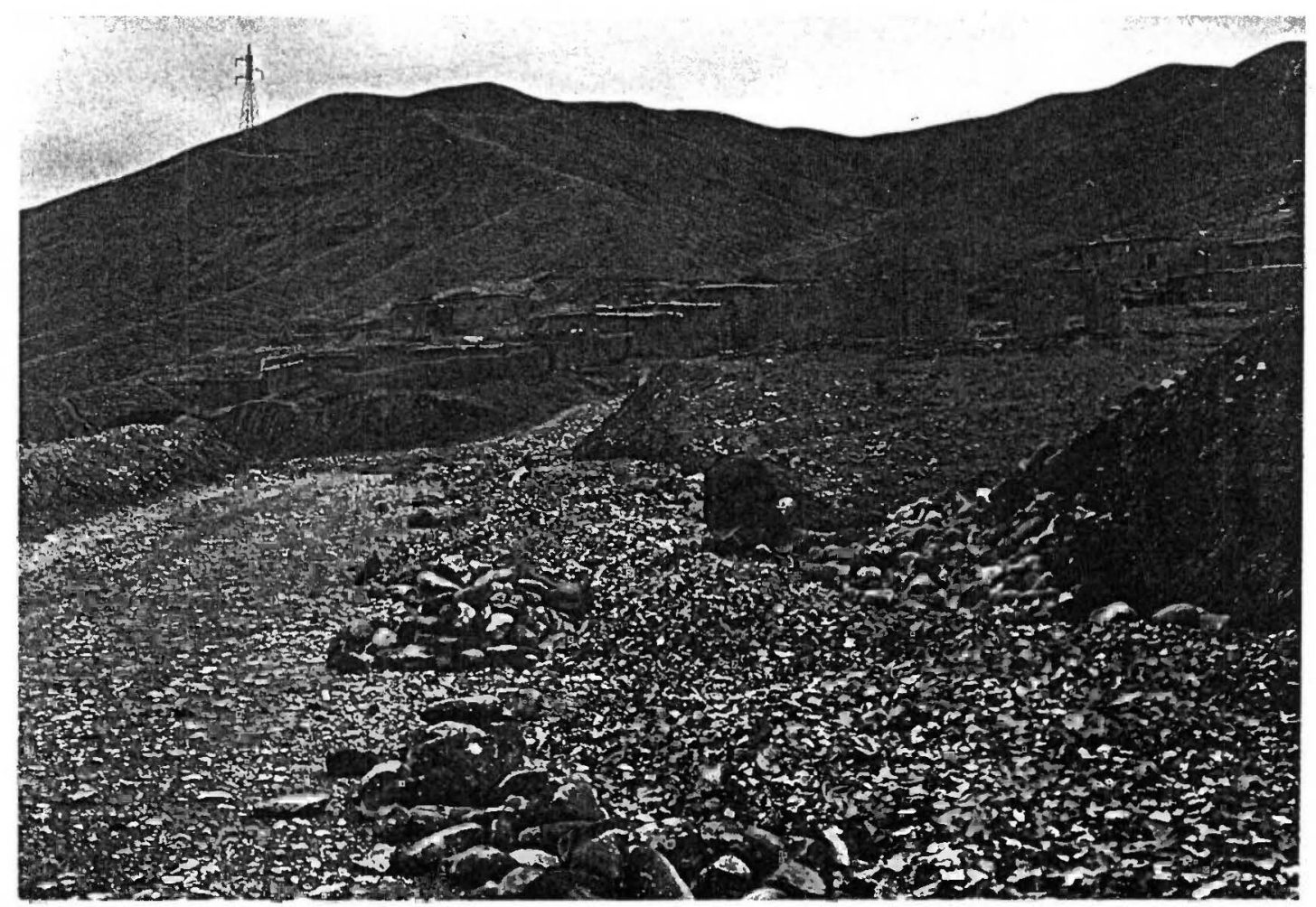

Preparation for black-topping the new Surkhab-Khanoza road, Baluchistan. 


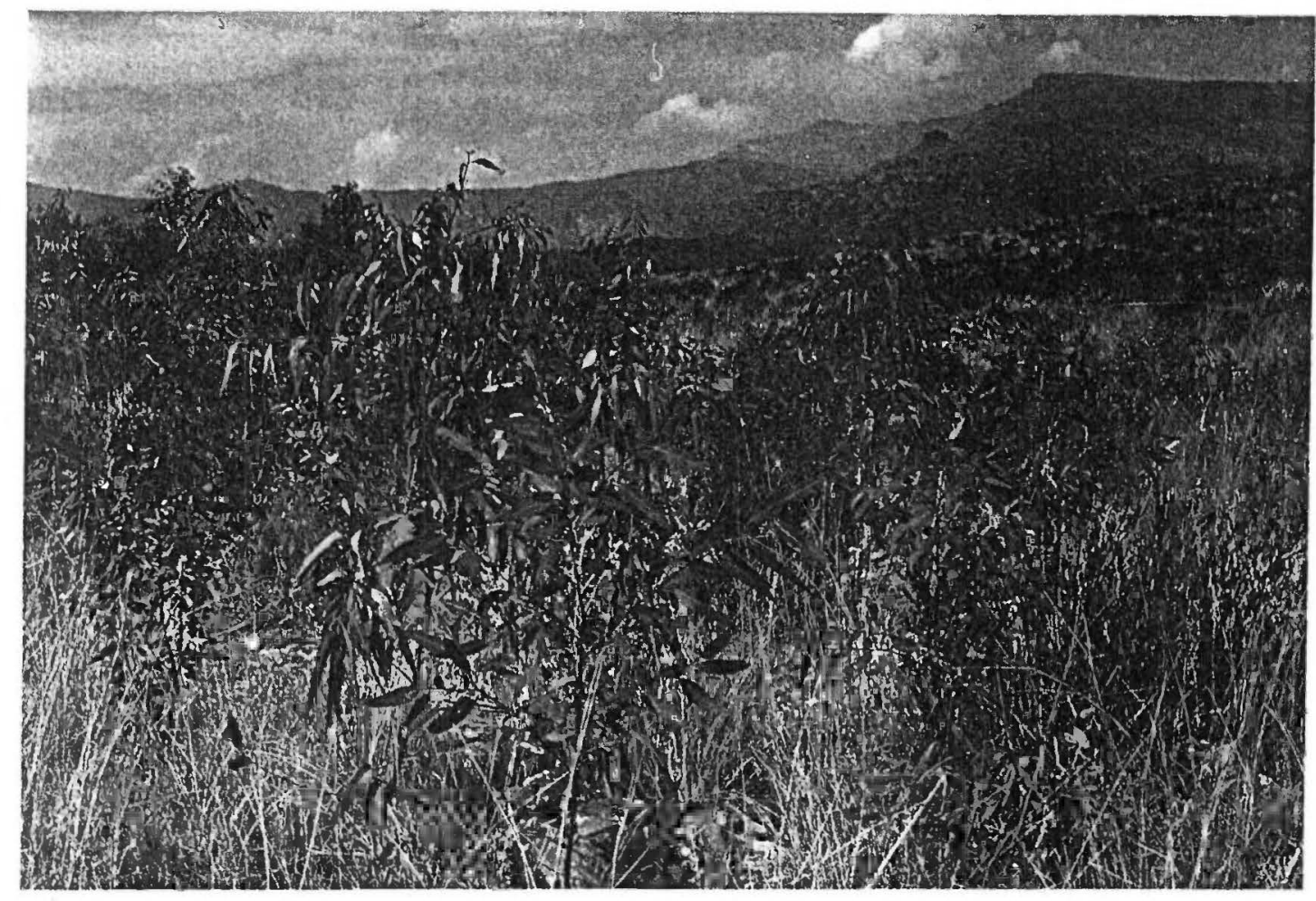

Well established Eucalyptus, with a high survival rate, Dalan block of Kohat Reafforestation sub-project, NWFP.

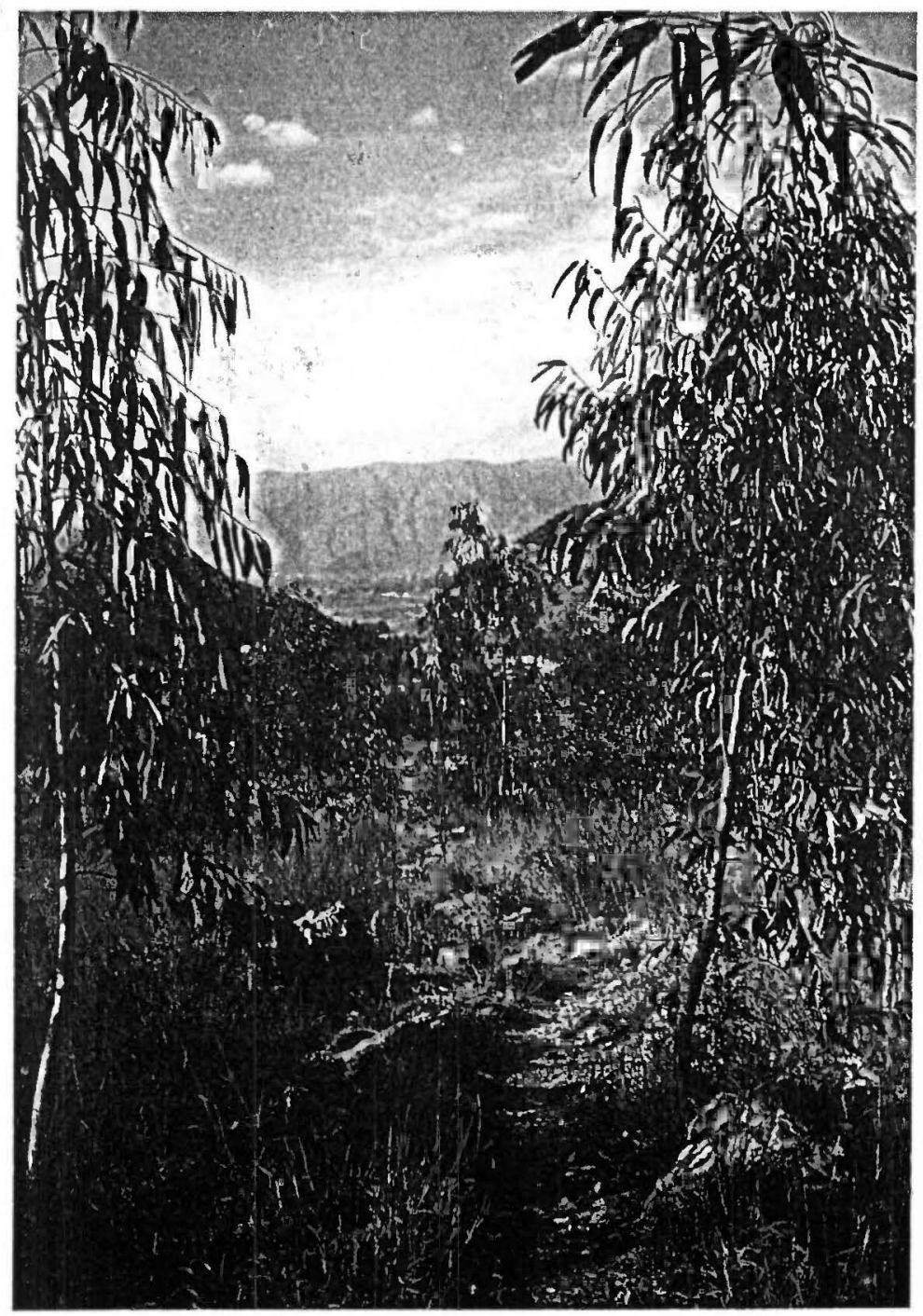

Eucalyptus on steep land in Hangu State Forest block of Kohat reafforestation sub-project, NWFP. 


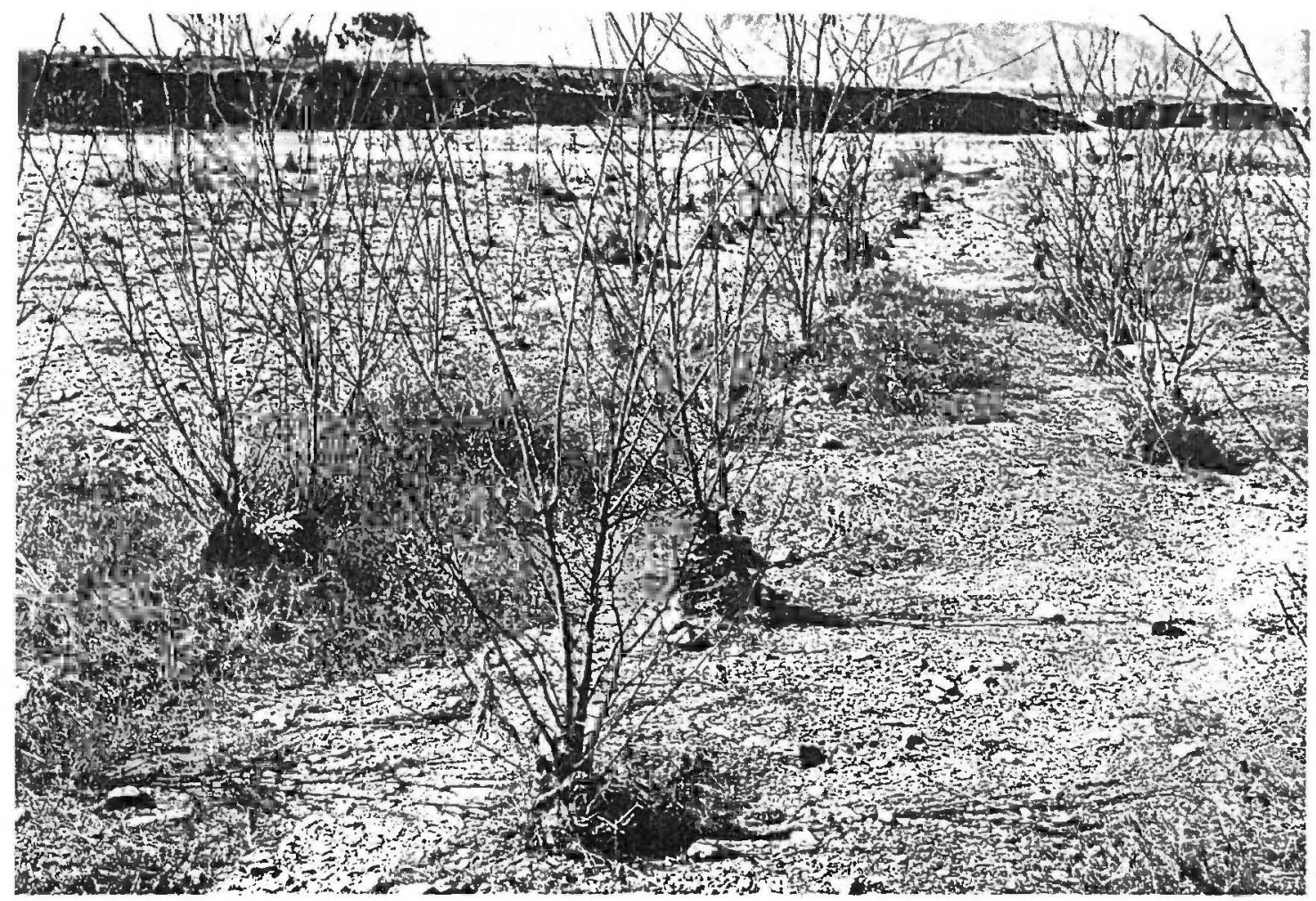

Well established Robinia, Soka Nullah sub-project, NWFP.

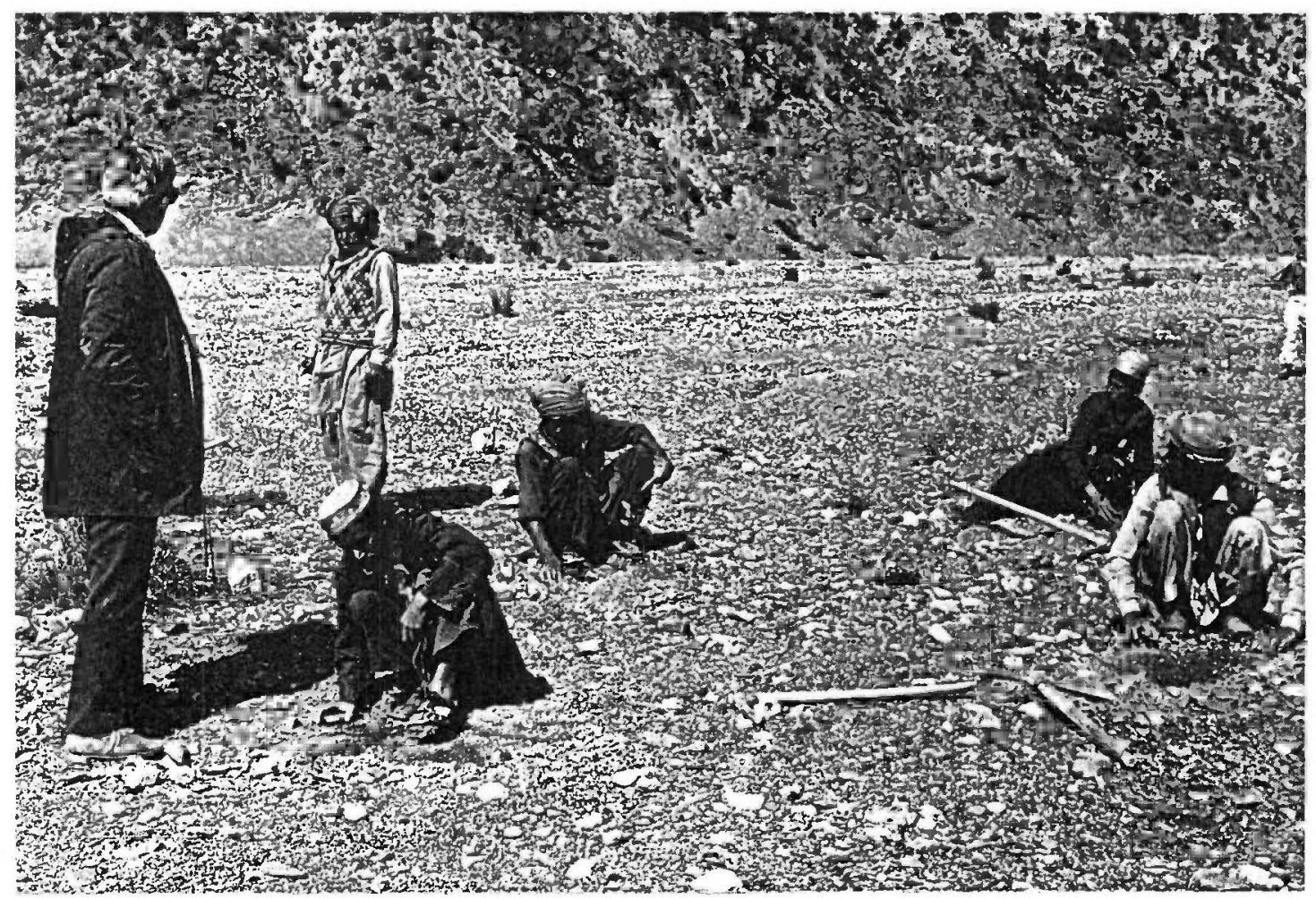

Afghan refugees planting Eucalyptus, Soka Nullah. 


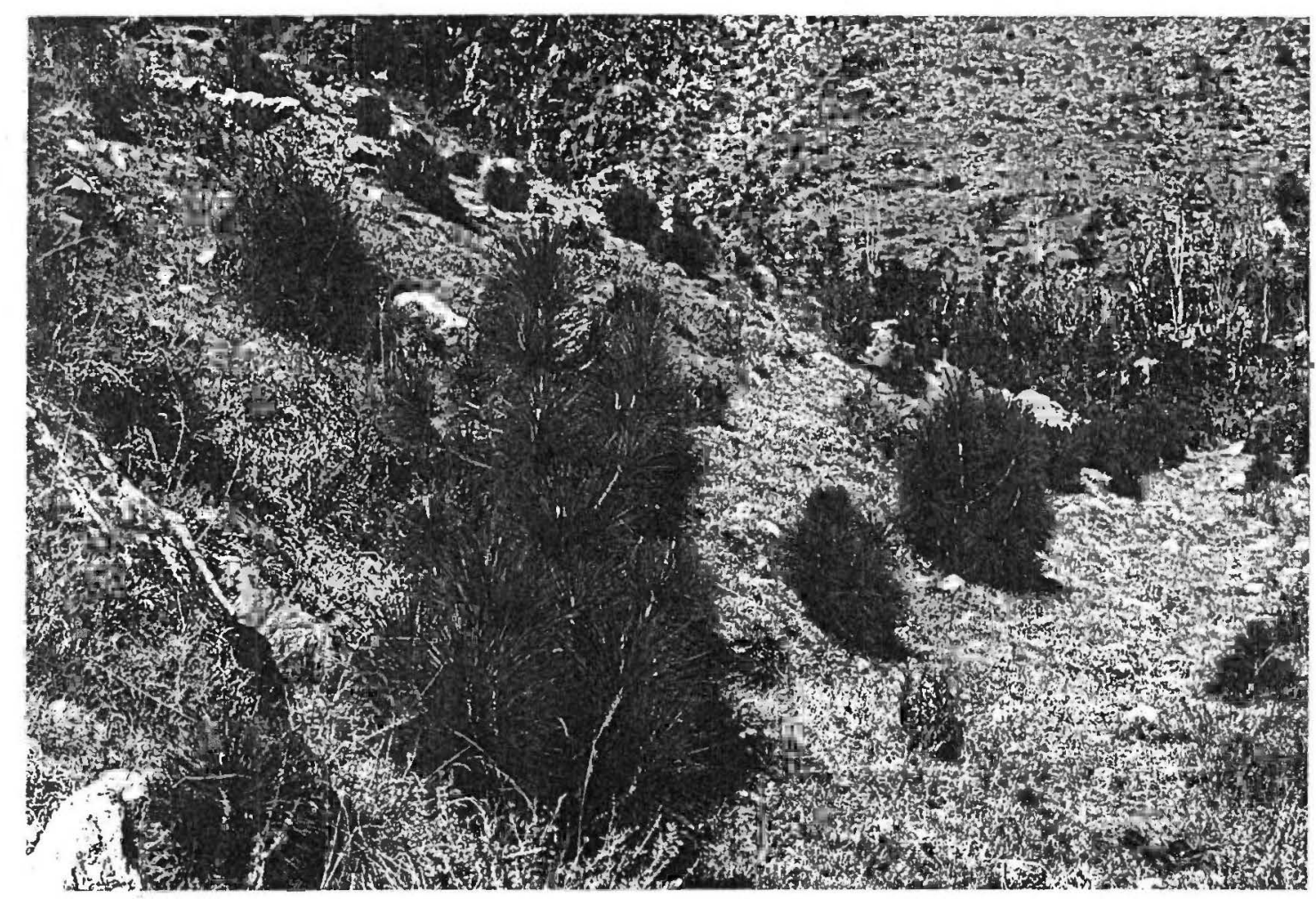

Well established Chir Pine trees, Soka Nullah.

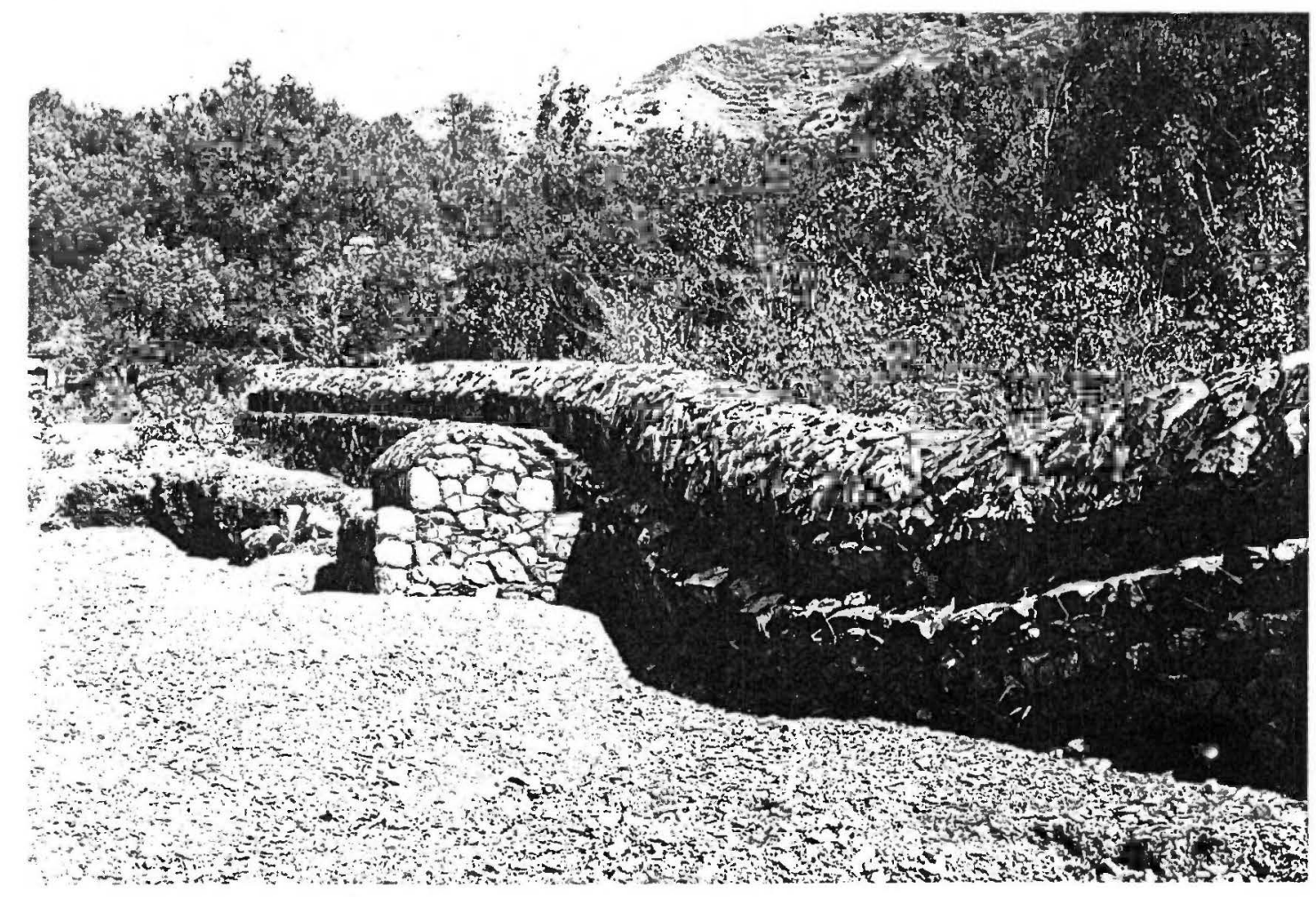

A partly under-mined nullah-training wall, upper reaches of Soka Nullah. 


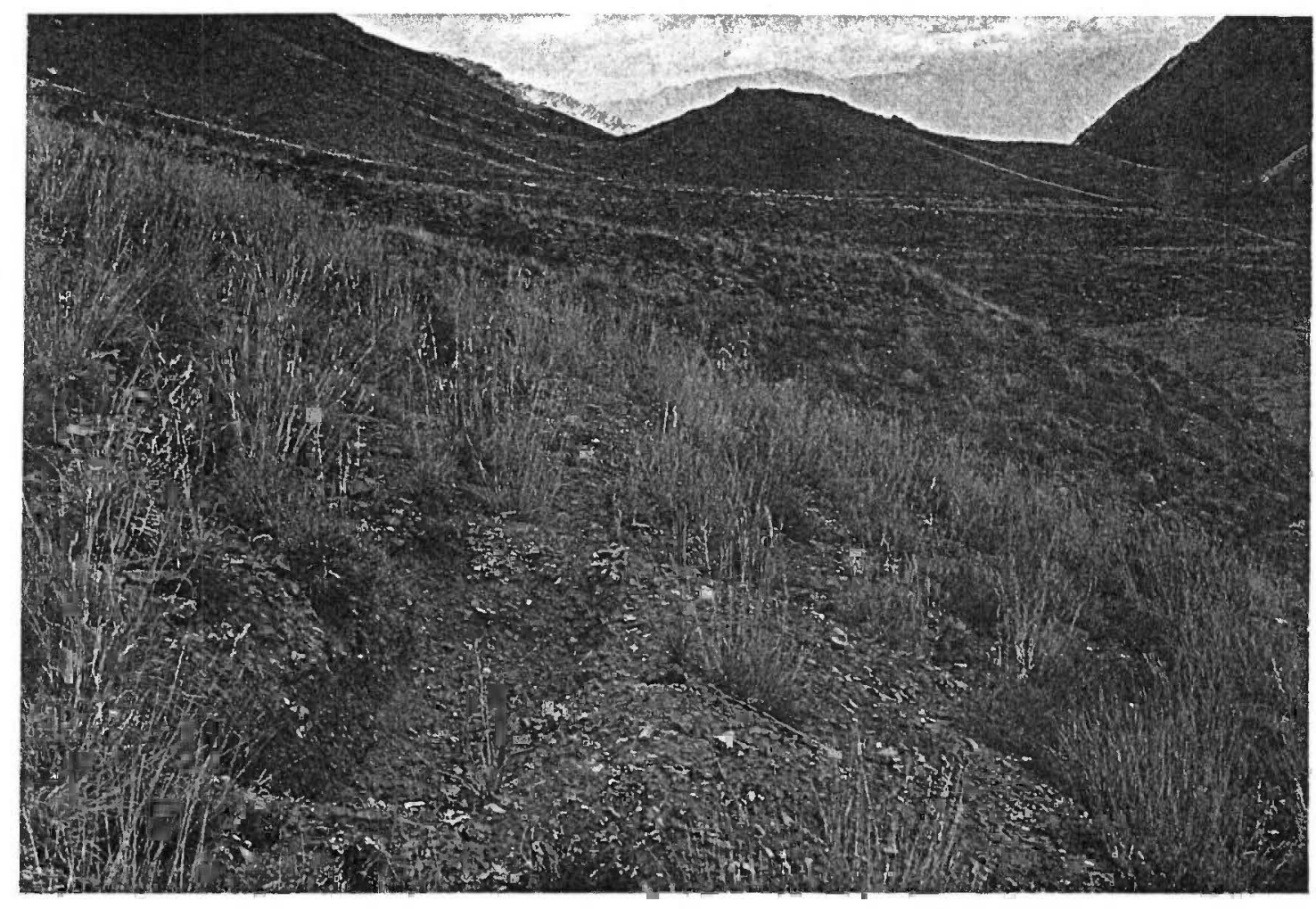

Re-established vegetation at Karkhasa sub-project, Baluchistan. Contour trench in foreground.

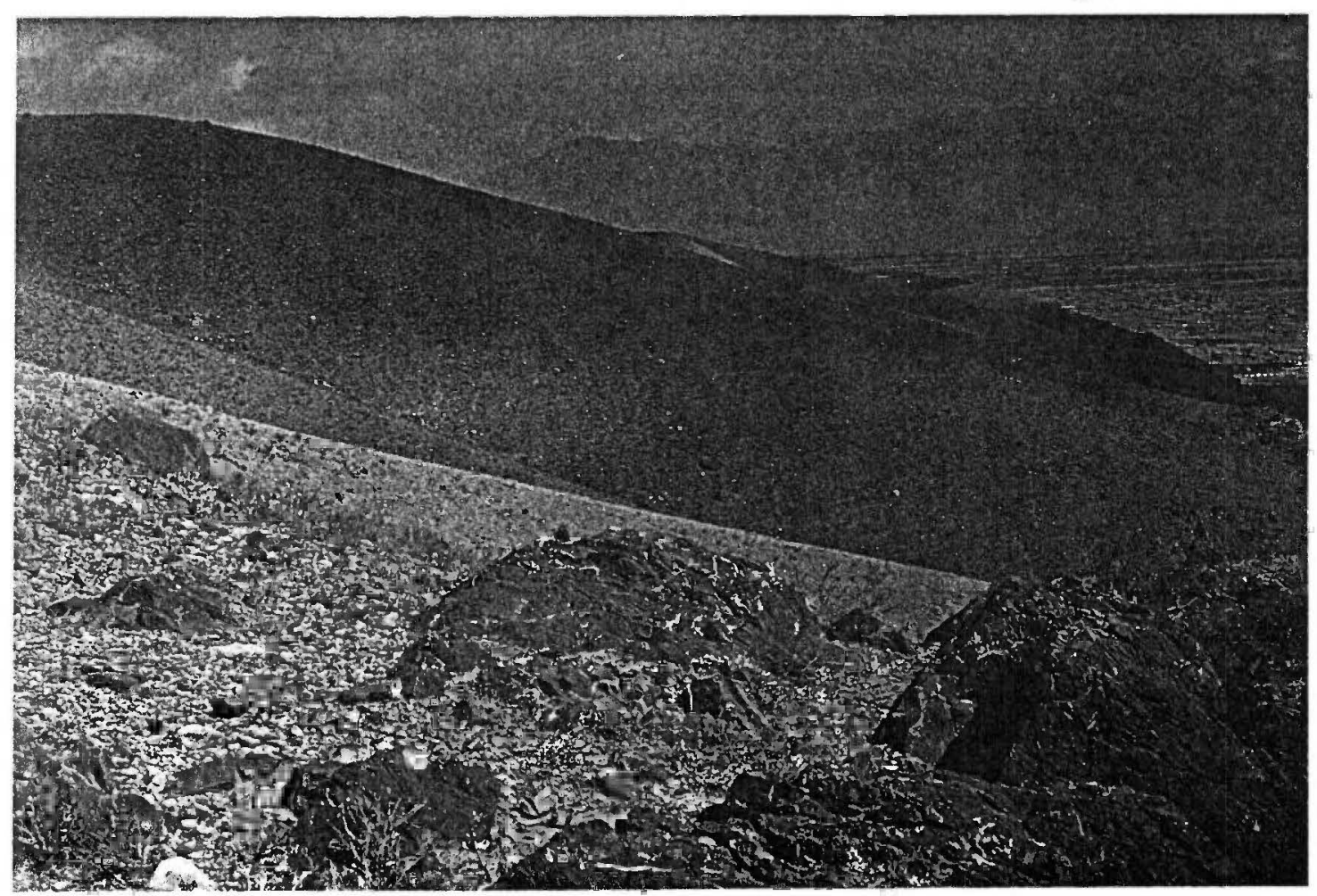

Totally denuded land immediately outside the Karkhasa sub-project. 


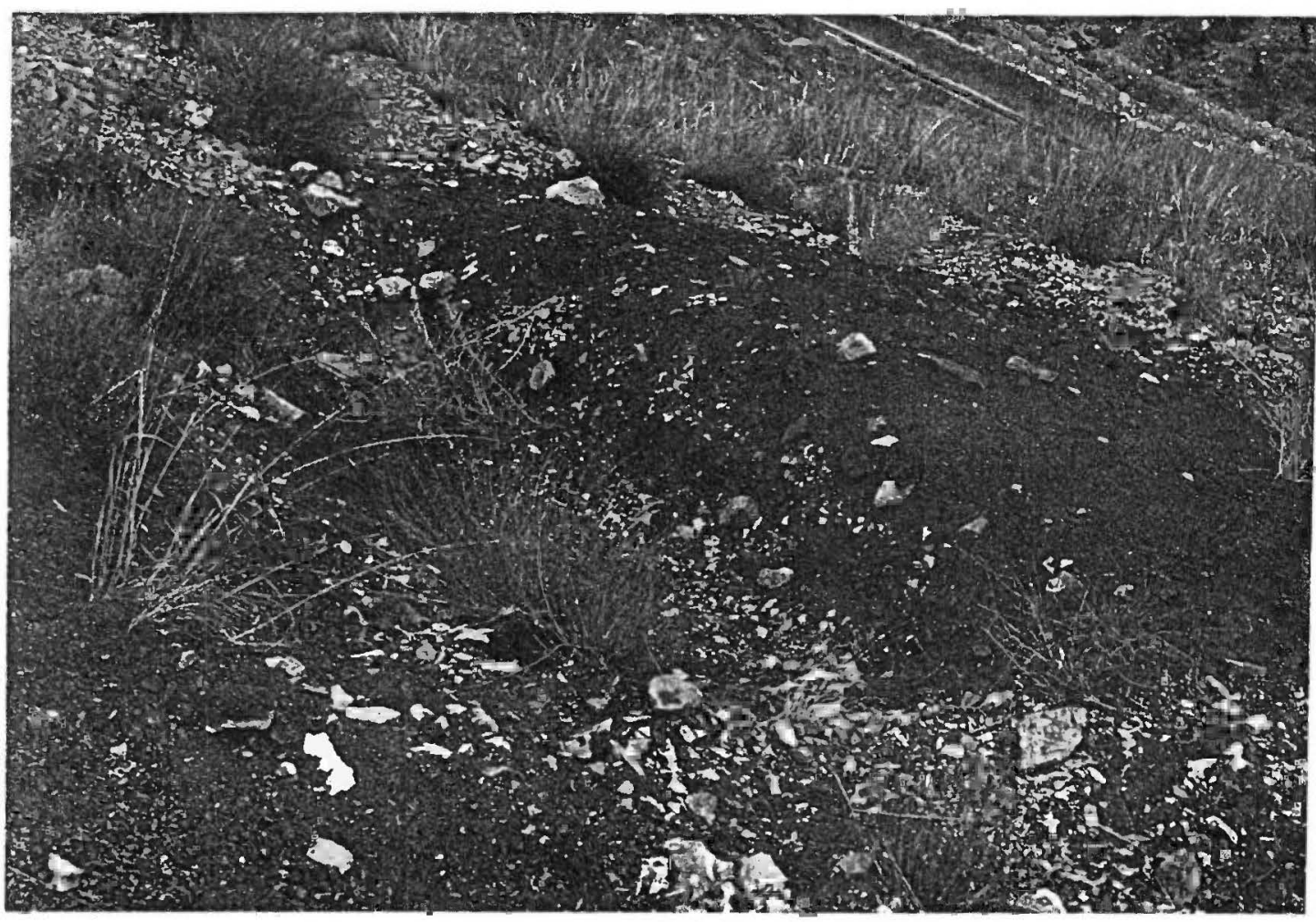

A collapsed contour trench at Karkhasa, excavated in shale-derived material.

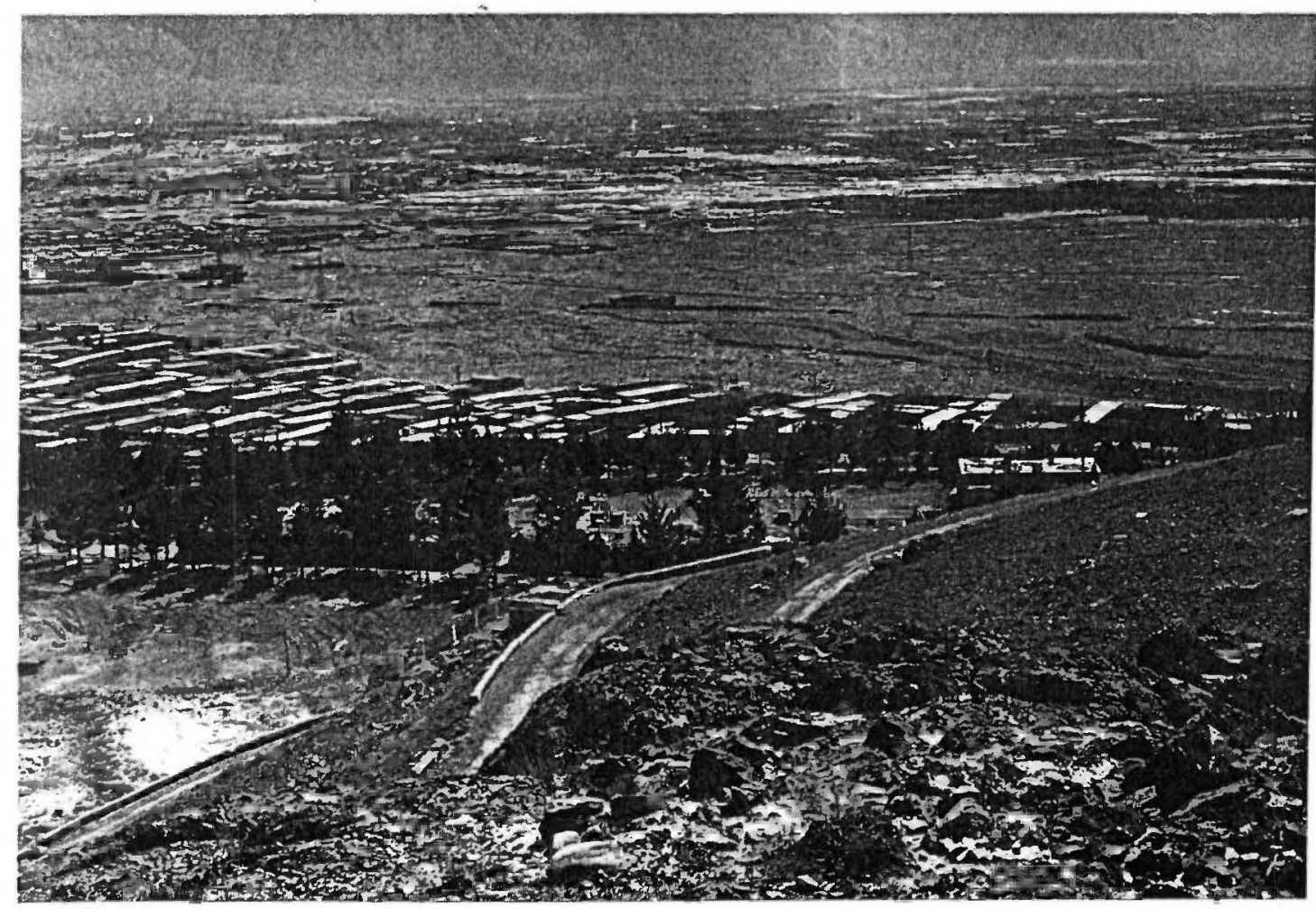

Housing immediately below the exit from Karkhasa valley, and vulnerable to floods but undamaged after the great storm of August 1986. 


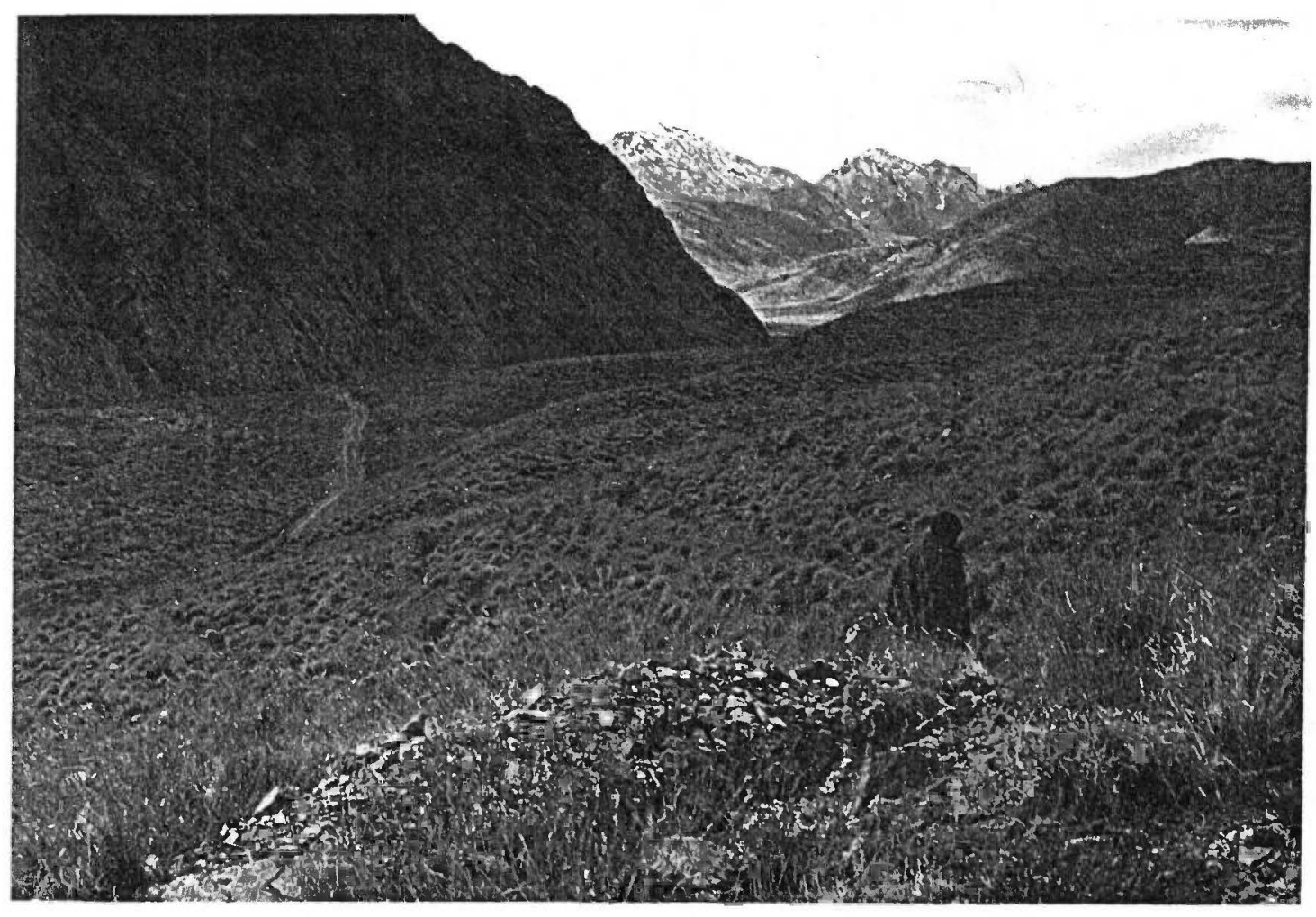

View of Karkhasa valley, within sub-project area, indicating its recreational value.

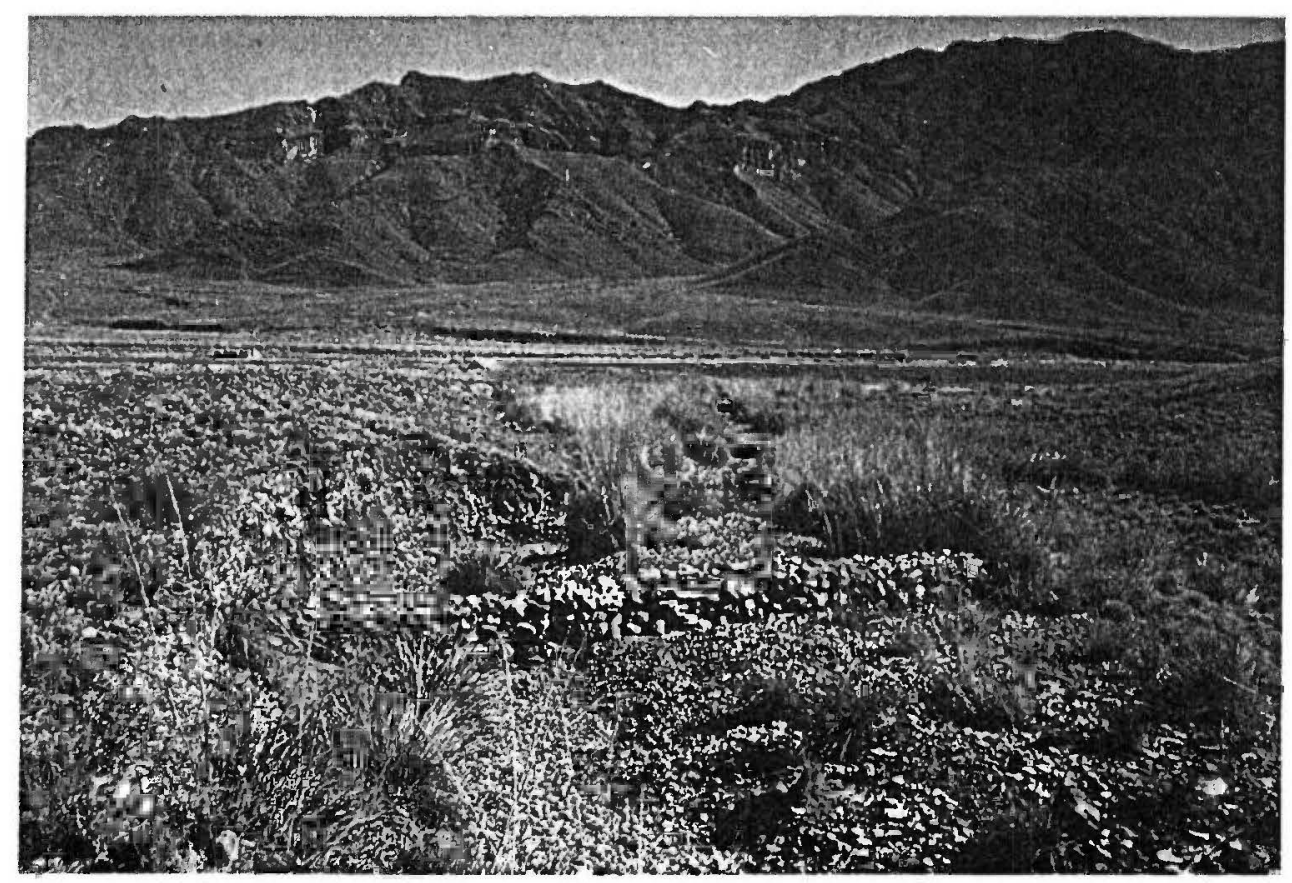

Kohar sub-project, Baluchistan, showing regenerating rangeland vegetation. 
5.3.1 Impact elements capable of direct measurement in this sector include the following:
(a) Water Resources - groundwater or surface.
(b) Vegetation Cover - forest or rangeland.
(c) Soil erosion.
(d) Wildlife

5.3.2 Significant inter-relationships exist, of course, between (a), (b), and (c), and less directly with (d). Other impact elements, such as reduction in the flood hazard, may in theory be measurable but cannot be quantified directly, in the present context, in relation to the sub-projects of the IGPRA Program. Research (e) may also provide important data.

(a) Water Resources

Groundwater, or groundwater recharge, is of course measurable in a number of ways. In the present situation, however, the groundwater situation is rather complex (see 4.3, and in more detail in the Evans report). From this it has been concluded that direct observations of groundwater levels within sub-project areas could not yield valid information as to the direct effects of treatments within them, except possibly over a very long period of years. It has therefore been recommended that attention should be directed towards measurement of surface run-off as a more relevant indicator of environmental impact.

Surface run-off can be measured in a number of ways. For present purposes, three methods are relevant:

- $\quad$ measuring total run-off from a watershed unit
- $\quad$ measuring run-off from experimental or sample mini-watersheds
$\quad$ measuring run-off from sample plots.

Two of the sub-projects lend themselves, in theory, to measurement of run-off from the whole watershed management unit - Soka Nullah in NWFP and Karkhasa in Baluchistan. In practice, this type of measurement seems feasible only at Karkhasa. The Soka Nullah itself, in its lower reaches before draining into the Tarbela reservoir, flows in a wide braided channel. Construction of works to record total flows would be both difficult and expensive. Surface flows from Karkhasa, in contrast, exit through a narrow gorge which makes stream gauging simple. Recommendations for doing this have been set out in the Evans Report. Crest gauges were proposed for measuring peak discharges, with once-a-month current metering to gauge the base flow run-off. These proposals were endorsed in the Working Paper on watershed management prepared at the time of the Staff Appraisal Report for the Second IGPRA Program.

The development of experimental watersheds to measure surface run-off (and soil loss) under different types of watershed management treatments has been proposed by the Pakistan Forest Institute (PFI) for a site in the Quetta Valley near Karkhasa. These are discussed further $(5.3(\mathrm{e}))$. The use of very small 'micro' watersheds, or permanent run-off plots, has been recommended by Hudson ${ }^{4}$ as a general way of measuring surface run-off and soil loss under different plant cover or conservation treatment situations. These latter are essentially small enclosed areas draining into tanks designed to contain both

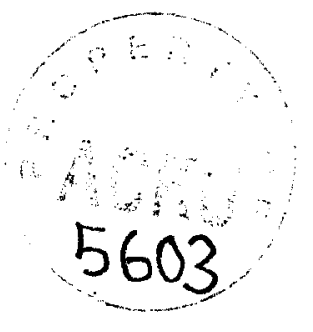


surface water and sediment, the amounts of both of which can be directly measured. The sites can be permanent, are relatively cheap to establish, and could be set up in each sub-project - both in NWFP and Baluchistan. If all runoff and soil loss trials are to be concentrated on one set of experimental catchments, then those catchments must be most carefully selected as fully representative, otherwise their results may not have wide application. This is a real risk (referred to again at 5.3 (e)) and a rather strong argument for concentrating on small run-off plot measurements in all First Program subprojects, and later in Second Program schemes.

The only specific information relating to run-off from any sub-project has been provided from Karkhasa. Winter rainfall recorded there from November 1986 to April 1987 was 6.2 inches. Of this it is estimated that just over $73 \%$ infiltrated the ground (directly or via trenches) with surface run-off being less than $2 \%$ - the balance being lost by evaporation. These estimates of course refer to a period when no really large storms occurred. The balance between infiltration and runoff might have been rather different during the storm of August 1986, when over 3 inches $(79 \mathrm{~mm})$ of rain was recorded over 16 hours. This was the storm which caused immense damage in the Bolan gorge and elsewhere, yet at Karkhasa there was no appreciable flood out of the narrow exit gorge - and at a time when trenching had only achieved an average density of 28 trenches per acre as opposed to the planned 55 .

\section{Measuring Vegetation Cover.}

Plant cover, from forest to ground cover (grasses etc) obviously has a major influence on surface run-off and soil erosion. The other important element here is the measurement of vegetation in relation to range management. Measures such as those described in (a) above would provide information on the former. Measurement of vegetation for range management purposes - an issue of key Importance in Baluchistan - requires different measures. These are essential to quantifying the beneficial impact of watershed management In relation to livestock production.

The basic requirement is to record the changes in rangeland vegetation which follow watershed management treatments in terms both of quantity (surface coverage and bulk) and quality (species composition). Continuous recordings of both elements, including periodic cutting of sample areas to determine bulk and nutritive status, provide both estimates of rate of recovery of rangeland under protection and assessment of 'safe' carrying capacity for livestock - and hence projections of economic benefits. The methods are essentially simple, consisting of permanently established 'line transects' and (usually) rectangular sample areas (quadrats), often linked together. Costs of establishment are minimal, but regular and accurate monitoring is essential. The methods recommended to be applied to sub-projects in Baluchistan, derived from Dorothy Brown's ${ }^{1}$ standard work on the measurement of vegetation, were set out in the Working Paper ${ }^{10}$ on watershed management already referred to. This kind of monitoring is quite essential in relation to assessing environmental impact and the identification of economic benefits. 
Reduction of soil erosion is clearly a matter where the environmental impact of afforestation and watershed management sub-projects is potentially beneficial. The relative impact, which varies considerably between sub-projects in NWFP and in Baluchistan, and even between sub-projects in each Province, has been discussed in qualitative terms in 4.2 and 4.3. Flood protection sub-projects also have a clearly beneficial impact in this context, as described in 4.4. In no case, however, is the actual impact quantifiable at the present time.

In the case of afforestation and watershed management sub-projects, the effect on soil erosion could be measured in essentially the same ways - and at the same time - as have been described for surface water run-off. The recording of changes in degree of soil erosion, by continuous recording of small sample watersheds or from small permanent run-off plots, will obviously be most important where present risks, or incidence of soil erosion, are high. This applies particularly in Soka Nullah in NWFP, and will also apply to those subprojects located in the higher rainfall areas of NWFP in the Second IGPRA Program. In the semi-arid sub-projects in NWFP, the incidence of soil erosion is much less, as described in 4.4. It does not therefore seem necessary to propose such measurements in these areas. Even in the one location where steeper land is being treated in this region (the 2,000 acre block in Hangu Forest), the general situation (with stony or rocky surface to the land, and good plant cover now established) is such that permanent plots established now may provide little worthwhile information. There are, however, small areas in this block of land where softer rocks outcrop. These are clearly subject to erosion at the present time, but appear to be too small in extent to make recording worthwhile.

Sub-projects in Baluchistan, though mostly reasonably stable in respect of soil erosion, also have localised areas where soft rocks outcrop - the Ghazij shales, for example. Such outcrops can be seen at Karkhasa, and their high erodibility Is drastically demonstrated at the Kach dam at the northern end of Quetta Valley, whose immediate catchment consists largely of such rocks. The establishment of permanent run-off plots, which could also measure soil loss, is however strongly recommended because of the importance of measuring changes in surface run-off as plant cover increases with protection and management. Measurement of soil loss from such plots would also serve as a check on any soil erosion developing from the installation of contour trenches, especially in areas of relatively steep slopes where the density of trenches needs to be higher to be effective in controlling run-off from larger storms and where the potential risk of erosion is also higher. The only negative impact of a sub-project, in respect of soil erosion, so far observed has been a limited amount of gully erosion generated at Kohar by the forest road built through the middle of the area. This could quite readily be corrected.

(d) Wildlife

No systematic observations of the impact on wildlife have been undertaken. To date it is possible to make only some rather general observations.

In NWFP, there has been a striking recovery (or increase) in the populations of black partridge - and to a lesser extent the grey partridge - in both Hangu Mazri and Kohat sub-projects. Mazri palm areas seem to provide a very suitable habitat for these species. The only reservation which can be expressed here is that grass cover could become so high and dense as to make the environment less suitable. A similar problem could effect the hill partridge (chukor), a bird of 
the foothills but thriving in a rather open situation. Increased cover could reduce the suitability of an area for this species (e.g. the lower or drier western parts of Soka Nullah). Eucalyptus plantations do not usually encourage wildlife, so that extensive areas planted to these trees would not have a positive impact. Very few, if any, larger animals remain, and in such a situation protection may achieve little if there is no remaining wild population to take advantage of it. Soka Nullah could provide a habitat for urial sheep, goral, and - in the drier areas - chinkara gazelle. Barking deer - still to be found in the hills near Islamabad - could be another species suited to Soka Nullah. Urial sheep and Chinkara gazelle could also be suited to Kohat sub-projects.

It is worth noting here that Conservator Forests (Wildlife) in NWFP has proposed a wildlife refuge at Nizampur, near Peshawar. This would consist of a 1600 acre fenced area, and could be stocked from Punjab Province and possibly from Kohat. A PC-1 has been prepared, with a budget of Rs 9 million. Apart from its intrinsic value, this refuge could play a part in restocking subproject areas where wild populations have disappeared. It would be good to see this idea supported.

In Baluchistan, the only sub-project likely to have a major impact on wildlife is Karkhasa. Karkhasa adjoins the Hazar Gangi-Chiltan National Park, which was created some 8 years ago though protective measures started 2 years earlier. A substantial reservoir of wildlife has been built up in the Park, the most important success being with the population of markhor, now estimated at 350 head. Other mammals include wolves, foxes, jungle cat, and porcupine, and there are a considerable number of birds and reptiles. Being adjacent to Hazar Gangi, the now protected area of Karkhasa can readily attract wildlife from the Park, so that populations protected there can further expand. Already the hill partridge (chukor) has become a common bird at Karkhasa, and the expanding population of predators (particularly foxes) suggest that a variety of wildlife is on the increase.

Regular counts of wildife are undertaken at Hazar Gangi and it should be possible to extend these to Karkhasa or to train sub-project staff to undertake them - especially as both areas are managed by the Baluchistan Forests Department.

(e) Research

Specific experimental work offers another means of obtaining data needed for the quantification of environmental impact in the field of watershed management.

During the last year (1987) of the First IGPRA Program, the Pakistan Forest Institute (PFI) proposed a range of experimental work in Baluchistan - mainly located in the Quetta Valley - with the object of evaluating the effects of different watershed management treatments. Both small-scale and large-scale investigations were proposed.

The large-scale experiment proposed was to monitor water balances in a pair of larger watersheds. The Evans report supported the proposal in principle, but was unable to recommend its implementation, in terms of man-power and cost, at the present time. Collation of information from other ongoing projects in Baluchistan was recommended instead, leading via hydrologic analysis to provision of a framework within which the effect of watershed treatments could be evaluated. 
On the smaller-scale, the PFI proposals envisaged a number of small areas (mini-watersheds) situated outside and close to the Karkhasa sub-project. These aimed at comparing several levels of treatment (different densities of contour trenching) by measuring surface run-off and sedimentation. These proposals were reviewed by Evans and the watershed management consultant on the Second IGPRA Appraisal Mission, and certain changes in emphasis were recommended. In essence, these aimed at ensuring a comparison between no treatment at all, simple protection by fencing, and treatment by contour trenches. It was felt that these were the critical comparisons to be made, rather than differences between levels of treatment - differences which might well prove difficult to evaluate with significant results. The types of structure and methods of recording suitable for such experimental miniwatersheds were also indicated.

Since early 1987, problems in relation to the sites selected have arisen, mainly due to local unwillingness to allow them to be fenced off. New sites will need to be found. Meanwhile PFI have prepared a new program of investigations which is expected to be presented shortly to the Baluchistan Government. This will include the systematic measurement of changes in vegetation as well as work on experimental watersheds. PFI already have some plots established in Quetta Valley aimed at assessing the effects of the planting of different tree species and a range of other land uses.

Any such experiments will take time to produce results, and there will then arise the question of extrapolation - how widely can any results be applied to the range of sub-projects either operating or planned. Parallel experiments (small paired watersheds) could similarly be set up in Soka Nullah, but the variation in conditions between the sub-projects in NWFP - and particularly those included in the Second IGPRA Program - suggest that results from Soka Nullah would have little extrapolative value.

It would seem better to concentrate on a simpler (and less expensive) approach by setting up a range of small permanent run-off plots - as referred to in 5.3(a) and (c) - combined with direct measurement of changes in vegetation. Such plots could be set up in all sub-projects.

\subsection{IRRIGATION AND FLOOD PROTECTION SECTOR}

5.4.1 The sub-projects in NWFP were all concerned directly with flood protection, as described in 4.4. Their environmental impact lies in preserving land, housing and infrastructure from the loss or damage which floods have caused in the past - or which are likely to cause in the future. Quantification of such impact depends on meaningful records of flood damage in the past and projecting these into the future. The feasibility of doing this depends on the availability of data on past losses and damage, and on the credibility of future projections. The apparent lack of factual data on past losses presents one problem for projection of future damage. Another difficulty relates to the fact that most damage occurs only at times of major floods, which themselves are erratic in their timing. The frequency and magnitude of floods will also depend on whether or not degradation of the upper watersheds continues, on whether conservation measures become effective enough to make serious impact, and on variations in climate.

5.4.2 The acquisition of adequate data to quantify the physical benefits of flood protection schemes looks, therefore, to be rather difficult. For Second IGPRA Program projects, it would seem worth-while to attempt, through the good offices of the NWFP Irrigation Department primarily, to seek the acquisition of data on land and property losses during recent years at each sub-project site, with a view to attempting quantification of impact. 
5.4.3 The one sub-project in this sector in Baluchistan is the remodelling of the Shebo Headworks canal system. Impact here can quite clearly be quantified in terms of the increased area of land which can be irrigated by the remodelling and de-silted system, whose capacity, as explained in 4.5, has been increased approximately seven-fold, and which will be further increased, under the Second Program, when at least three of the four storage tanks are de-silted. This last work is already in progress, at tanks 3 and 4. Data on areas irrigated and crops produced are available via the Irrigation and Revenue Departments, so that no special data collection is required. It is unfortunate, in this connection, that the winter season of 1987-88 produced so little rain, allowing for the irrigation of only 200 acres of rabi crop.

\subsection{ROADS SECTOR}

5.5.1 There is little to be said in connection with the quantification of physical environmental impact in this sector. In both NWFP and Baluchistan, quantifiable impact will largely be possible only in economic or social terms - via traffic counts and records of employment. Only in one case, the new Surkhab - Khanozai road in Baluchistan, where the sub-project appears to have stimulated new orchard (apple) development, can environmental impact be quantified. Data for assessing this development should be obtainable through Agriculture or Revenue Departments within the next year or two. 


\subsection{CONCLUSIONS}

6.1.1 Environmental impact of the sub-projects in the First IGPRA Program varies considerably in nature between the three sectors into which the sub-projects fall (forestry and watershed management, irrigation and flood protection, and roads) and sometimes between sub-projects in each sector. In some cases insufficient time has elapsed for any beneficial impact to be clearly seen, especially in the case of forestry and watershed management projects. This time element also applies in the case of one irrigation sub-project, the Shebo Headworks canal remodelling scheme in Baluchistan, where lack of rainfall has so far prevented the potential beneficial impact from being realised.

6.1.2 In the forestry and watershed management sector, there has been some difficulty - in the context of watershed management in Baluchistan - in relation to objectives. The initial over-riding objective, as discussed in 4.3, was groundwater recharge. It is now clear that there are a range of possible objectives, and a priority ranking of these is needed (e.g. rangeland development rather than groundwater recharge, at Maslakh) if benefits are to be more clearly linked to the specific measures undertaken. During the Second IGPRA Appraisal Mission, such ranking of objectives was indicated for all revised PC-1's of Baluchistan sub-projects, so that treatments could be planned with such objectives clearly in mind.

6.1.3 The problem of evaluation is compounded by the absence of an impact monitoring system in the First IGPRA Program. Even if such a system had been set up, however, many of the impacts which could or should be monitored would not yet have provided valid usable data. Many years of study are likely to be needed, in the context of watershed management, before environmental impacts can be fully assessed.

6.1.4 Nevertheless, looking at the whole range of sub-projects in First IGPRA, the overall impression is of positive environmental impact. This beneficial impact has been immediate in the case of the flood protection projects in NWFP, and of the roads projects - with some minor reservations in the latter case related to increased ease of access, in Baluchistan, leading to further degradation of natural vegetation in the vicinity of major refugee settlements. As already noted, potential beneficial impacts of the Shebo Headworks sub-project have not been immediately realised because of low rainfall since the sub-project was completed.

6.1.5 Reafforestation and erosion control sub-projects in NWFP appear to be having clear if so far unquantifiable beneficial environmental impact, perhaps most clearly seen to date in the Soka Nullah sub-project and in the Hangu State Forest block of the Kohat Reafforestation sub-project. The three watershed management sub-projects in Baluchistan all demonstrate beneficial impact since the sub-projects were initiated, with Karkhasa and Kohar showing impressive regeneration of rangeland vegetation and, in Karkhasa, of wildlife. Kohar, with one year more of protection and treatment than Karkhasa (and also being in an area of rather higher rainfall) shows the most impressive effects in relation to vegetation regeneration. The beneficial impact of the third subproject in Baluchistan, Maslakh, is less obvious: partly because the vegetation had been particularly seriously affected by refugee pressure, many perennial plants having been removed completely for fuel and also because it is a comparatively dry area. Maslakh is also the one subproject where a more realistic assessment of priority objectives might have led to a different approach to conservation and possibly to the realisation of beneficial impact at substantially lower cost: though it has, of course, provided employment for a considerable number of refugees a major objective of the project. 
6.1.6 Looking at the program from the regional viewpoint, the overall impact must necessarily be small, though there is some evidence - particularly, to date, in NWFP - that local appreciation of the importance of watershed management and reafforestation has been stimulated by the work so far undertaken. With the wider geographical spread of sub-projects in the Second IGPRA Program, such local understanding, leading to much more direct cooperation and involvement, could develop considerably. This is by no means unimportant.

6.1.7 Within the context of the areas which have most suffered from the impact of large numbers of refugees and their livestock, however, the impact of the First IGPRA sub-projects is much more obvious and in some cases dramatic. They provide evidence, so far essentially visual rather than measurable, that the very great environmental damage suffered in Pakistan can, albeit slowly in some respects, be repaired.

\subsection{RECOMMENDATIONS}

6.2.1 The recommendations which follow reinforce and in some cases add to those made, in connection with the Second IGPRA Program, in the Bank's Staff Appraisal Report of September 1987 and the technical Working Papers which supported it. They are concerned mainly with reafforestation and watershed management sub-projects, since these are the projects where evaluation is most difficult and where data to base such an evaluation on is largely lacking. The recommendations are summarised from the discussion of impact elements set out in Section 5.

(a) Maps

Accurate topographic maps are needed urgently for all sub-projects, in both First and Second Programs. Sub-projects should be located and their limits defined, in terms of single natural watershed units, or at least within clearly recognisable watershed units. Effective planning, monitoring and evaluation, and management, depends to a very real extent on this basic requirement.

(b) Surface run-off and eroslon control

No direct measurement of these two very important elements have yet been made. It is recommended that simple permanent run-off plots, measuring both surface run-off and soil loss, be established in all reafforestation and watershed management sub-projects (except for mazri plantations). Records of these plots, linked with rainfall data recorded on sub-projects, would provide evidence of the effect of conservation treatment and afforestation as project implementation and management proceeds.

It can be argued that the type of data obtained from the run-off plots which have been recommended is needed in a wider context, given the importance of watershed management and rangeland improvement throughout the North and West of Pakistan; and that the initiation and carrying through of such work is the proper responsibility of the PFI rather than of a relatively small-scale and short duration project such as IGPRA. This is a reasonable point of view; but the recommendation is maintained since the IGPRA sub-projects, taking the First and Second Programs together, provide a remarkably wide geographical spread of different situations, and allow measurements to be taken in controlled conditions which exist hardly anywhere else at present. 
(c) Measurement of changes in vegetation or plant cover

Simple line transect and/or quadrats for measurement of changes in plant cover and composition are recommended for all watershed management subprojects in Baluchistan. Such measurements will provide evidence both of the effectiveness of treatment measures and data for evaluation of rangeland in terms of future livestock production and rangeland management.

(d) Establishment of priority objectives

This recommendation applies particularly to watershed management subprojects in Baluchistan, and could affect the extent and intensity of application of the single most controversial conservation measure so far adopted: the installation of contour trenches. A more selective approach in this context has already been adopted for the sub-projects included in the Second IGPRA Program and has been discussed in more detail in Section 4.3 of this report, in the 1987 Working Paper on watershed management, and in the Evans Report.

(e) Access to new Saranan Camp across the Shebo Main Canal

Damage to the canal by passage of refugees between the main road and the camp has been described (4.4). It is recommended that a bridge be constructed to allow passage of refugees and their transport.

(f) Damage to the road through Surkhab refugee settlement

Apart from damage to the road caused by traffic, lack of adequate provision for drainage is creating problems. It is recommended that additional drains or culverts be installed. Buildings are already appearing along the first stretch of the new Surkhab-Khanozal road: a wider reservation to prevent buildings encroaching too closely on the road is recommended. 


\section{ANNEX A}

\section{TERMS OF REFERENCE FOR THE ENVIRONMENTAL CONSULTANT}

1. On or about February 8, 1988 you will arrive in Pakistan where during the ensuing three weeks you will carry out an assessment of the environmental impacts of the First Income Generating Project for Refugee Areas (IGPRA I). You will work under the guidance of Mr Naseem (Bank) and will liaise with $\mathrm{Mr}$ Myren, a consultant, assisting GOP/SAFRON in writing Project Completion Report and with staff of the World Bank Resident Mission in Pakistan during your stay in the country.

2. The IGPRA I had, as a primary objective, the amelioration of the negative environmental impacts imposed by the influx of Afghan refugees. You will assess the extent to which the sub-projects undertaken have contributed to the accomplishment of this objective. In those cases in which insufficient time has elapsed to make a full appraisal, you will make a tentative assessment based on evidence available to date and will recommend practical steps which may be taken to facilitate fuller assessment being made at a later date.

3. In carrying out the environmental impact assessment you will pay particular attention to the impact of the soil conservation and watershed management projects undertaken by Forest Departments in NWFP and Baluchistan and to the monitoring and evaluation measures currently in place to allow the assessment of the Impact of these sub-projects. In addition, you will assess the extent to which measures have been taken in these and other sub-projects (e.g. the canal road sub-projects) which will control the imposition of similar damages in future.

Consultant's Itinerary:

8

9-11

February 1988

February

12 February

13 February

14 February

15 February

16 February

17 February

18 February

19 February

20 February

21 February

22 February

23 February

24-26 February

$27 \quad$ February
Arrived Islamabad

Discussions and meetings World Bank, UNHCR

and SAFRON, Islamabad. Report drafting

commenced.

Travelled by road to Peshawar

Meetings with Irrigation and Forest Departments

Visits to Flood Protection and Canal Road

sub-projects. Visited Pakistan Forest Institute.

Visit to Reafforestation and Mazri Palm

sub-projects in Kohat.

Travelled to Quetta via Islamabad.

Meetings with Forests, Irrigation and

Communication and Works Departments.

Visited Maslakh sub-project by helicopter.

Visits to Hazar Gangi National Park and

Karkhasa sub-project.

Visits to irrigation and roads sub-projects.

Travelled to Islamabad.

Report drafting.

Visit to Soka Nullah sub-project, NWFP.

Report drafting and discussions with

World Bank staff and UNHCR.

Returned to UK. 


\section{ANNEX B}

\section{A note on Rangeland Vegetation in Baluchistan}

\section{GENERAL OBSERVATIONS}

Rangelands in Baluchistan have been used for production of livestock for a very long time. Virtually all rangelands, certainly those within the region where IGPRA sub-projects are or will be located, have been overgrazed and were deteriorating well before the Afghan refugees arrived. Botanical records early this century described a substantially richer vegetation, including more grasses and a considerable number of legumes - Medicago spp. were apparently common but have now virtually disappeared - and there were many more trees and shrubs. This long-term deciine has of course been greatly accelerated in those areas most affected by the influx of refugees. An already impoverished vegetation has been in places almost eliminated by wholesale cutting and uprooting, especially of perennial and woody plants. The dominant plant of much of the drier rangelands (Artemisia) is unfortunately well-suited for use as fuel, and its wholesale removal is particularly woryying. Its regeneration from seed is not well understood.

\section{RANGELAND VEGETATION WITHIN SUB-PROJECT AREAS}

The type and condition of rangeland vegetation within the three First Program subprojects varied, from the start, considerably. Karkhasa and Maslakh are both in relatively dry areas with Artemisia - dominated rangeland. Karkhasa actually has rather more rain than Maslakh, probably because of the orographic effect of the Chiltan Hills. This effect is especially marked in the Hazar Gangi National Park, and in part accounts for the very striking regeneration of rangeland vegetation on the sloping fans which have been protected by fencing and guards for up to 10 years. A more recent extension of the fence line, about 3 years ago, provides a comparative demonstration of rate of regeneration.

Maslakh sub-project area was probably the most damaged by refugees of the three. Wholesale removal of perennial plants was clearly widespread: the holes where the plants once grew can still be observed. Almost certainly most of the plants removed were Artemisia, which is perhaps why the slowly recovering rangeland appears now to have a high proportion of chenopod species - Indicating a greater degree of aridity than may in fact be the case.

Kohar, by contrast, has a higher rainfall and lies more in what might be described as grass-dominated rangeland. The principal grasses were Cymbopogon and Chrysopogon spp. The latter, a valuable and palatable grass, has tended to disappear with over-grazing, being replaced by the unpalatable Cymbopogon. The problem is now to get Chrysopogon back. Will protection simply lead to the spread of Cymbopogon?

These are the kind of questions which need asking, but do not seem to have been asked within the IGPRA Program. They are being looked at by the USAID/ICARDA unit based at Quetta, and it is urged that closer links should be forged between this team and the Forestry Department. It may well be that regeneration by protection will not be enough, and that deliberate reseeding of valuable species may be needed in addition. Work in this area is also under consideration by ICARDA, including the possible use of exotic arid climate plants such as Atriplex canescens (fourwinged salt bush), a plant native to Arizona. Encouragement of woody shrubs is important. Planting of such shrubs is included in present sub-project programs, but perhaps needs to be emphasised as opposed to the planting of some tree species whose early survival rate is low and whose long-term development may be in doubt. It has already been recommended that trees, in particular, should be restricted to the more favourable locations in future sub-project areas, using individual pits rather than contour trenches. The practise, universally applied throughout First IGPRA sub-projects, of planting or seeding all contour trenches with trees or shrubs is seen as a complicating factor if the primary objective is rangeland development (as it should be at Maslakh and Kohar). This practise must delay for several years the time when the regenerated range can be re-opened for livestock production, even if overall successful establishment is only of the order of $10 \%$, as expected. It would be better, in all sub-projects where rangeland development is a priority or major objective, to plant trees and shrubs in blocks at the most favourable sites of their

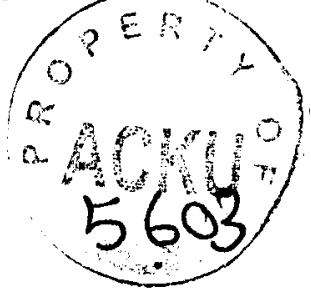


establishment. Such blocks could be fenced separately and thus provided with continued protection after the area is re-opened for livestock. In Maslakh, in addition, the species being planted should be re-examined. Some species (such as Robinia, which was not among the trees recommended at the time of appraisal of the First IGPRA Program) have virtually no chance of survival in such arid conditions, while others may be somewhat location specific (Pistacia khinjuk and, perhaps Iamarix). Shrubs such as Atriplex and Haloxylon are wholly appropriate - and are suceeding well where already planted. Other suitable species, also establishing reasonably well, include Prosopis and the native wild almond. Attention could also be given to planting in sites where moisture conditions may be especially favourable, such as the edges of nullahs and along minor drainage lines, and behind the small earth dams or bunds.

Effective protection during the rehabilitation period is of course essential. At neither Kohar nor Maslakh was fencing well-maintained - this also applied in parts of the Kohat Reafforestation sub-project and at Hangu Mazri. Evidence of incursion of livestock at Maslakh was seen both from the air (tracks) and on the ground (animal droppings, grazed plants and browsed young trees). Such incursions, to a lesser degree, were observed at Kohar. Close supervision of these two rather remote areas is, of course, not easy. As more sub-projects are developed and more land is therefore enclosed, the pressures on the degraded rangeland outside must increase. Effective protection will become both more difficult and more necessary.

\section{RANGELAND VEGETATION OUTSIDE SUB-PROJECT AREAS}

As just mentioned, pressure on already degraded rangeland outside project areas will increase as these expand, though project areas will still represent only a tiny fraction of rangelands in the region. Perhaps of more concern Is the expanding destruction of natural vegetation by refugees from the main settlement areas, an expansion which could be increased by the improved access provided by rehabilitated or new roads provided under the IGPRA Program.

At present no attempt at all is made at restricting these destructive activities, which must present very serious problems for Paklstan In the future. Recovery of these devastated areas can at best be very slow. It is the search for fuel which is most damaging, since plants are wholly removed rather than being simply cut. Unless some alternative fuel can be provided, if is difficult to suggest a positive approach to this problem. Coal is plentiful in Baluchistan, but does not seem to be an appropriate fuel for the type of cooking appliances used by Afghans, especially for baking bread. Without any such alternative, prohibition of transport of cut brushwood by mechanical transport - which would be the most direct way of dealing with the expansion of exploitation of the natural vegetation, even if it resulted in initial violence - does not seem even theoretically feasible. Yet it cannot be in Pakistan's interests simply to adopt a 'laisser-faire' attitude in the face of this continually deteriorating situation. 


\section{ANNEX C}

Baluchistan.

Watershed management objectives and conservation treatment issues in

1. The main elements of environmental impact in this context have already been listed (4.3.2). They are repeated here for convenience. These impact elements can also, of course, be considered as objectives in terms of watershed management. They are as follows:

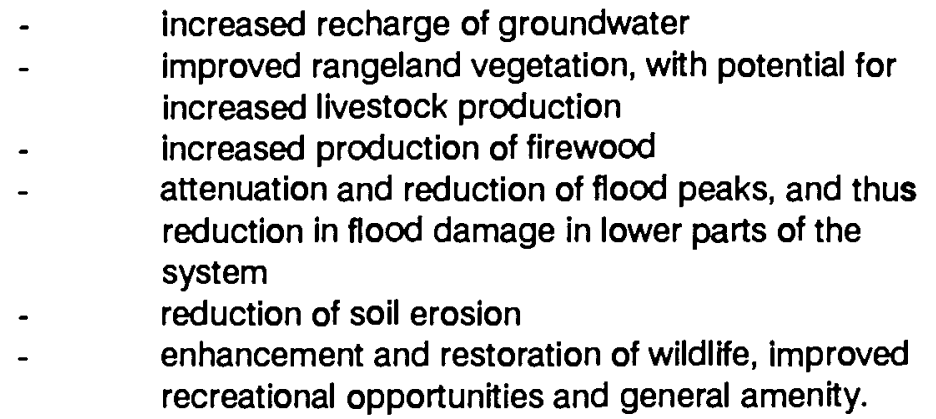

2. The principal objective for all three First IGPRA Program watershed management sub-projects in Baluchistan was recharge of groundwater. This approach was initiated by Leitch and continued by Williamson, whose work was unfortunately interrupted when he was kidnapped and removed to Afghanistan. This work was reviewed by a consulting hydrologist (Evans) appointed by the Bank in March 1987. Evans' conclusions were that the rationale for enhanced groundwater recharge could not be accepted because of weaknesses In the assumptions made which tended to invalidate any conclusions based on them. He further pointed out that groundwater changes are often the result of a wide range of varying influences - In particular non-homogeneity in aquifer properties - and generally would not be expected to indicate directly the changing influence of any single control measure. It was also originally proposed that measurement of groundwater recharge should be tackled mainly by the installation of wells and recording changes in water-level: an exercise which, Evans advises, could produce meaningful results only over a period of many years, since other activities in the region (especially the increased installation of tube-wells) could mask trends in groundwater levels and so make it very difficult to isolate the effects of watershed treatments. It would be better to concentrate on the measurement of rainfall and surface run-off.

4. The Evans report concluded that the case for enhancement of groundwater recharge by installation of contour trenches had not been made, but that there was a much stronger case for the effect of the trenches on reducing surface run-off - especially from heavy storms which can result in such serious flood damage lower down the system. (He felt, in this context, that continuous contour bunds would be even more effective than contour trenches, but did not recommend replacing contour trenches by such bunds because of the difficulty of constructing them properly using unskilled labour).

5. The relationship between watershed management objectives and conservation treatments actually installed - and it should be emphasised that the only such treatment about which reservations have been expressed is the installation of contour trenches - by considering the Maslakh sub-project, which is rather different from the other two, Karkhasa and Kohar. Both the latter are largely confined to natural watershed units (Karkhasa wholly so), and include land of variable slopes, some of them quite steep. Maslakh sub-project, by contrast, 
occupies a roughly rectangular 4,500 acre block of land on the north side of a steep rocky ridge. The bulk of the area consists of relatively gently sloping pledmont or alluvial fan material, dissected by shallow stony or gravelly drainage lines. Much of the land has slopes of 10 per cent or less. The fan material is generally less stony (except locally) than at Karkhasa or Kohar. Rainfall is low, with an annual average of about 7 inches $(170-180 \mathrm{~mm})$. The range vegetation had been devastated by refugees from the nearby camp, with much of the perennial vegetation destroyed by digging up of roots for fuel.

6. There was therefore a clear rationale for protection and regeneration of this rangeland, an important resource with gentle topography lending itself to relatively easy management. The approach to treatment of this sub-project has, however, been dominated by the objective of groundwater recharge and this has led to the construction of the highest density of contour trenches on any sub-project - 2,400 cft per acre capacity, as opposed to 1,650 at both Karkhasa and Kohar. Moreover it is not clear what the impact of increased groundwater recharge in this area would be. In the valley below the termination of the alluvial fans there is agricultural land where 'barani' cultivation is practised, with very limited local use of irrigation water from hand-dug wells. No doubt some improvement of this agricultural land could be effected if groundwater recharge proved to be significant and if wells were developed on the project side of the valley (present wells are all on the other side of the valley, towards the Afghan border, and would not be affected by groundwater recharge generated by the project). But the primary objective at Maslakh should surely have been the regeneration of the range resource and livestock production from it. Had this been the primary objective from the start, it is difficult to see how the present close coverage of contour trenches could have been planned or justified. As already pointed out in Evans' report, the case for groundwater recharge by use of contour trenches has not been established - and at Maslakh, where much of the land area has slopes of less than 10 per cent, the density of trenches needed to control surface run-off from the larger storms (Evans' principal justification for them) would have been quite low. His maximum recommendation for slopes between 5 and 10 per cent was about $750 \mathrm{cft} / \mathrm{acre}$, with none at all on slopes less than 5 per cent. Without a clear case for groundwater recharge, therefore, the density of trenches installed at Maslakh has been excessive. In this connection it is worth noting that, of the $13 \mathrm{dug}$ wells in existence when the project was visited in February 1988, only 4 had water (at between 30 and 40 metres). All the others were dry. No measurements of rise or fall in water level have been made since the inception of the sub-project.

8. An immense amount of work has gone into Maslakh, and it seems hard to suggest at this stage that much of it may have been misdirected. Nevertheless, it is necessary, in the interests of the effectiveness of future work in this field, to make this point rather strongly. There is no evidence that the high density of trenches has initiated any new soil erosion - indeed the nature of the topography would make this unlikely: but the concentration of trenches cannot be a plus factor in connection with range management. Even though a re-think at Maslakh seems to be needed, however, there has already been some beneficial impact in relation to rangeland regeneration, though slower than at Karkhasa and Kohar both because of earlier excessive degradation and lower rainfall. Recovery is also somewhat impeded since fencing and guards have not proved wholly successful in excluding grazing livestock, though wholesale removal of plants for fuel has stopped. 


\section{ANNEX D}

\section{REFERENCES}

1. Brown, D. (1954, reprinted 1963). Methods of surveying and measuring vegetation. Commonwealth Agricultural Bureau, London, UK.

2. Dyksterhuis

E.J. (1949). Condition and management of rangeland based on quantitative ecology. J. Range Management, 2,104-15.

3. Evans, T.E. (1987). Report of Consultant Hydrologist, Second Income Generating Project for Refugee Areas.

Sir M MacDonald and Partners, Cambridge, UK.

4. Hudson, N. (1971). Soil Conservation, Batsford.

5. Leitch, C.J. (1983). Design of Works and monitoring program for Baluchistan watershed management sub-project. Sheddon Pacific Pty. Ltd., Melbourne, Australia.

6. Williamson, R. (1986). Impact of watershed management works on hydrology, near Quetta. Sheddon Pacific Pty. Ltd., Melbourne, Australia.

7. World Bank (1983). Staff Appraisal Report, First Income Generating Project for Refugee Areas.

8. World Bank

(1987). Staff Appraisal Report, Second Income Generating Project for Refugee Areas.

9. World Bank

(1987). Working Paper for Forestry Component of Second Income Generating Project for Refugee Areas (NWFP and Punjab).

10. World Bank (1987). Working Paper on watershed management component of Second Income Generating Project for Refugee Areas. 